\title{
IGUALDAD ENTRE MUJERES Y HOMBRES TRAS 40 AÑOS DE CONSTITUCIÓN ESPAÑOLA
}

CRISTINA ZOCO ZABALA 
SUMARIO

1. INTRODUCCIÓN. 2. SIGNIFICADO FORMAL Y MATERIAL DE LA IGUALDAD ENTRE MUJERES Y HOMBRES: LA ARMONIZACIÓN DE LOS ARTÍCULOS 14 Y 9.2 CE. 3. IGUALDAD FORMAL: PROHIBICIÓN DE DISCRIMINACIONES DIRECTAS E INDIRECTAS POR RAZÓN DE SEXO. 4. IGUALDAD MATERIAL. 4.1 Medidas de acción positiva. 4.2 Medidas represivas con perspectiva de género. 4.3 Medidas antidiscriminatorias. 5. CONSIDERACIONES FINALES. 


\title{
IGUALDAD ENTRE MUJERES Y HOMBRES TRAS 40 AÑOS DE CONSTITUCIÓN ESPAÑOLA
}

\author{
CRISTINA ZOCO ZABALA* \\ Profesora de Derecho Constitucional \\ Universidad Pública de Navarra
}

\section{INTRODUCCIÓN}

Tras cuatro décadas de Constitución Española, se ha progresado en el reconocimiento de la igual calidad de especie humana de mujeres y hombres. La igualdad ante la ley (igualdad formal) como exigencia de prohibición de diferencias normativas por razones subjetivas, entre ellas el sexo (art. 14 CE) ha redundado en la derogación de normas que han ignorado en derechos a las mujeres con base en la atribución social de diferentes roles al grupo de población femenino (género) frente al masculino (discriminaciones directas). También ha repercutido en normas que han equiparado a los hombres y a las mujeres en la consecución de derechos-deberes, entendiendo que en las mismas circunstancias vitales presentes la asunción de deberes de cuidado por el grupo de población masculino permitía avanzar en la deseada corresponsabilidad parental.

La igualdad de trato ante la ley prohíbe, así, toda distinción normativa por razón de ser mujer o por las diferencias de roles socialmente atribuidas a ambos grupos de población en perjuicio de las mujeres (género); también proscribe la discriminación por indiferenciación que se produce cuando, la norma, pese a su aparente neutralidad, puede resultar discriminatoria en sí misma o en su aplica-

* Facultad de Ciencias Jurídicas. Universidad Pública de Navarra. Edificio Departamental Las Encinas. Campus Arrosadía. 31006 Pamplona. Email: cristina.zoco@unavarra.es 
ción, si, confrontada con realidades de facto diversas, supone un trato perjudicial para las mujeres (discriminaciones indirectas).

En el Estado social español la igualdad también tiene un significado material (art. 9.2 CE). Así pues, es posible establecer medidas de acción positiva, medidas antidiscriminatorias, o medidas represivas con perspectiva de género cuando las mujeres son desiguales en oportunidades o son discriminadas en ámbitos concretos de la realidad social presente.

La evolución de la realidad social también precisa que la ley armonice las exigencias del artículo 9.2 CE con las que dimanan del artículo 14 CE cuando el rasgo legal que hace desiguales en oportunidades a las mujeres (la maternidad) deja de ser atributo exclusivo del grupo de población femenino, en detrimento de los hombres transgénero (discriminación por razón de identidad sexual). Es preciso transformar las medidas de acción positiva para las mujeres en derechos que puedan solicitar ambos grupos de población.

La cambiante finalidad de esta medida de conciliación — la corresponsabilidad parental y no solo el descanso por parto- precisa, además, convertir tal derecho de descanso por parto en un permiso parental ejercitable de modo simultáneo o sucesivo por ambos progenitores. Pues el legislador debe precisar el máximo número de destinatarios a los que la ley se aplica (los progenitores con independencia del sexo, la identidad o la orientación sexual) de conformidad con su finalidad (la corresponsabilidad parental).

En este trabajo, se estudia la evolución de la pretendida igualdad efectiva entre mujeres y hombres en la legislación y en la jurisprudencia, desde el doble significado formal (art. $14 \mathrm{CE}$ ) y material (art. 9.2 CE) de la exigencia de igualdad constitucional.

Desde la perspectiva del mandato de igualdad de trato, se analizan las discriminaciones directas e indirectas por razón de sexo que han redundado en la derogación de normas (igualdad formal). También se estudia la discriminación contra las mujeres desde la coexistencia con otros motivos de discriminación que, por ello, originan una nueva forma de discriminación interseccional cualitativamente diferente a la que resulta de la suma de todas ellas. Se determina que la discriminación múltiple como nueva forma de discriminación interseccional cualitativamente diferente a la mera adición de todas ellas supone un mayor perjuicio personal para las mujeres afectadas. También se verifica la inexistencia de una ley transversal que proteja de forma más eficaz la especificidad de las discriminaciones ad personam que resultan de su análisis interseccional. El mayor perjuicio que comporta la discriminación por diversas razones subjetivas también debe derivar en una sanción que se adicione a las indemnizaciones que se deben abonar por la suma de las discriminaciones acumuladas. 
En lo relativo a la igualdad de oportunidades entre mujeres y hombres, se analizan las medidas represivas con perspectiva de género, las acciones positivas y las medidas antidiscriminatorias que persiguen eliminar las diferencias reales y efectivas entre mujeres y hombres que todavía persisten en ámbitos concretos de la realidad social presente (art. 9.2 CE). También se estudia la igualdad de oportunidades entre mujeres y hombres desde la perspectiva de otros criterios de prohibición de discriminación que se derivan de la evolución de la realidad social: la identidad sexual.

Desde la perspectiva de las diferentes políticas públicas llevadas a cabo para garantizar una igualdad real y efectiva entre mujeres y hombres se verifica que las medidas de acción positiva — sometidas a evaluación temporal de resultadosconsistentes en cuotas para mujeres en las listas que presenten los partidos políticos, o las medidas antidiscriminatorias que exigen porcentajes equilibrados de hombres y mujeres en los procesos selectivos que realizan los partidos políticos resultan conformes a los artículos 9.2 y $14 \mathrm{CE}$. Son acordes con el artículo $14 \mathrm{CE}$ porque tales procesos selectivos no se basan en criterios formalmente objetivos de mérito y capacidad; en definitiva, porque no existen pruebas objetivas intelectuales y emocionales para ser representante político, lo que impediría seleccionar solo a hombres o solo a mujeres. Tales porcentajes de mujeres, o de mujeres y hombres, exigidos en las listas de los partidos políticos también son conformes con el artículo 9.2 CE porque las cuotas se fundan en una realidad vital desigual entre mujeres y hombres que ha evidenciado una menor elección del grupo de población femenino en las listas que presentan los partidos políticos, lo que ha justificado la medida. Estas listas, además, no solo deben asegurar una composición paritaria por cada tramo de cinco puestos: también es preciso — en la línea establecida por otras Comunidades Autónomas- exigir una alternancia de sexos en cada tramo (listas cremallera), con el fin de evitar que la presencia de mujeres en los órganos de decisión quede al albur del número de escaños obtenidos por los partidos políticos. Además, estos porcentajes de mujeres y hombres no solo deben ser exigibles en las listas que presentan los partidos políticos; también tienen que ser preceptivos para todos los órganos del Estado cuya elección no se base en una objetivación formal del mérito y la capacidad sino en una relación de confianza para el desempeño del cargo (mesa y comisiones del parlamento, órganos de gestión de las administraciones, etc.).

La reciente inclusión en el Código Penal de la circunstancia agravante de género permite que el juez pueda aplicarla en todas las manifestaciones de la violencia ejercida contra las mujeres por su diferente valoración como seres humanos (transversalidad de género). Se analiza si tal medida debería de llevar aparejada la derogación de las normas penales que, conforme a la reforma opera- 
da por la LO 1/2004, de 28 de diciembre, de medidas de protección integral contra la violencia de género obligan al juez a incrementar la pena en los casos de violencia intrafamiliar no habitual, o de relaciones de pareja con o sin convivencia (lesiones, amenazas y coacciones) cuando la víctima sea mujer o persona especialmente vulnerable. Se concluye, sin embargo, que la violencia mayormente ejercida contra las mujeres en este ámbito sigue justificando el mantenimiento del preceptivo incremento penal que el juez tiene que determinar en tales supuestos de violencia; este incremento de la pena también debería ser preceptivo para la violencia intrafamiliar habitual.

En el ámbito laboral, los avances científicos han equiparado a hombres (transgénero) y a mujeres en un rasgo que antes los diferenciaba en la vida real (la maternidad). Se determina que la desaparición de la exclusividad de este rasgo en las mujeres permite convertir la medida de acción positiva en un derecho que puedan solicitar mujeres y hombres transgénero compatible con las exigencias del artículo $14 \mathrm{CE}$. La regulación de medidas de acción positiva en normas (art. 9.2 CE) debe armonizarse, así, con la generalidad y objetividad de la ley (la igualdad formal) que se proyecta en normas aplicables al máximo número de destinatarios posible cuando el rasgo jurídico que identifica a las personas desiguales en oportunidades (las mujeres) desaparece. La igualdad real y efectiva entre mujeres y hombres es fundamento para que la ley identifique a los individuos o a los grupos por la diferencia (el rasgo jurídico) que les hace desiguales en oportunidades en la vida real (art. 9.2 CE): la maternidad; sin embargo, tal exigencia debe armonizarse con la igualdad de trato que es presupuesto para que la ley identifique a las clases de sujetos, y no a los grupos (las mujeres) por el rasgo jurídico que los equipara — la maternidad — cuando dicho rasgo ya no es atributo exclusivo de las mujeres (art. $14 \mathrm{CE}$ ).

La garantía de la corresponsabilidad parental de los progenitores con independencia del sexo, la orientación o la identidad sexual también debe ser pretexto para convertir esta medida de acción positiva — todavía de titularidad de la madre- en un permiso parental que pueda ser disfrutado de forma simultánea o sucesiva por ambos progenitores (permiso parental por cuidado de hijo tras su nacimiento para ambos progenitores sustitutorio del descanso por maternidad). Dado que la finalidad de la norma ya no radica solo en el descanso de los progenitores biológicos sino el cuidado del niño en los primeros meses de vida resulta discriminatoria por razones ad personam (art. $14 \mathrm{CE}$ ) si no incluye a todos sus destinatarios (los progenitores).

Se ha evolucionado en normas para la igualdad real y efectiva de mujeres y hombres. Sin embargo, se avanzado mucho menos en educación en igualdad. El derecho fundamental a la educación tiene por objeto el respeto a los principios 
democráticos de convivencia y a los derechos y libertades fundamentales (art. 27.2 CE). Es preciso que la ley de educación incluya, de forma preceptiva, materias de educación en igualdad en todas las fases del currículo escolar. De tal forma, que la decisión sobre la formación e instrucción en igualdad, no quede al albur de la voluntad política.

\section{SIGNIFICADO FORMAL Y MATERIAL DE LA IGUALDAD ENTRE MUJERES Y HOMBRES: LA ARMONIZACIÓN DE LOS ARTÍCULOS 14

$$
\text { Y } 9.2 \mathrm{CE}
$$

El artículo 14 CE proclama la igualdad de trato ante la ley; proscribe así, toda diferenciación en la norma que por basarse en razones subjetivas expresamente tasadas (raza, sexo, religión, opinión) o por cualquier otra circunstancia personal o social, convierte tal distinción en discriminación.

El mandato del artículo 14 CE prohíbe toda discriminación en la diferenciación normativa ${ }^{1}$. Sin embargo, no consagra un derecho a la desigualdad de trato ante situaciones jurídicamente no disímiles, pues — señala la doctrina—, la ley ad personam solo puede ser «controlada» pero no «reclamada»; lo contrario significa que los jueces sustituyan su función de control de la finalidad, pertinencia y adecuación de las diferenciaciones jurídicas, por la de decidir por sí solos criterios para la creación de otras normas en atención, a la nueva identidad normativa demandada por algunos de los sujetos equiparados en la norma que se cuestiona $^{2}$.

1 «En la realidad social, la ley se encuentra con multitud de situaciones a las que no puede dar un trato igual. De hecho, casi ninguna ley afecta en su contenido de igual forma a todos los ciudadanos. Ésta es una situación imposible en una sociedad diversa como la actual, donde la disparidad y complejidad de los supuestos de hecho impiden tal clase de simplificación legal. Dada esta situación inevitable, los órganos de control de constitucionalidad han tenido que crear una construcción doctrinal para distinguir entre la diferencia de trato constitucionalmente admisible (diferenciación) y la que no lo es (discriminación)», Giménez GLUCK, D. (1999). Una manifestación polémica del principio de igualdad: acciones positivas moderadas y medidas de discriminación inversa, Valencia, Tirant lo Blanch, p. 33.

2 La doctrina es clara al respecto, al afirmar que «la igualdad ante la ley no consiente semejante fiscalización de la regla equiparadora (...) en razón a la propia estructura de la norma jurídica (la ley ad personam, en el caso límite, puede ser controlada, pero no reclamada) y para la preservación, inseparablemente, del componente esencial de la democracia constitucional que es la división funcional del poder público. División que resultaría desdibujada si los jueces fueran llamados no ya a controlar la finalidad, pertinencia y adecuación de las diferenciaciones jurídicas, sino a decidir por sí solos criterios para la creación de otras en atención, por ejemplo a la identidad ostentada por cualesquiera grupos. Asumida en esa hipótesis, sin límites discernibles, la "legali- 
La igualdad de trato, por tanto, prohíbe toda discriminación en la diferenciación establecida por la norma. La ley está llamada a diferenciar en la medida en que para la consecución de su finalidad —organizar la sociedad, o reducir la complejidad social—, precisa otorgar relevancia jurídica a unos criterios que identifican a unas clases de destinatarios y no a otros. Por ello, el mandato de igualdad de trato no impide que la norma establezca diferencias pero exige que el criterio de relevancia jurídica que identifica a quienes son destinatarios de la norma frente a quienes no lo son sea razonable, congruente y proporcional $^{3}$.

El mandato del artículo 14 CE determina que la ley, aunque diferenciadora, tiene que ser lo más general y abstracta posible, sin distinciones por razones subjetivas; solo basada en razones objetivas, entre ellas el mérito y la capacidad ${ }^{4}$. Así pues, la igualdad de trato exige que la ley otorgue relevancia jurídica a criterios que, por ello, identifican a clases de sujetos; pero prohíbe el establecimiento de diferencias en razón de «ser sujeto» o «ser grupo» en su identidad individual o colectiva.

Así mismo, la norma que otorga relevancia a criterios que, por ello, identifican a clases de destinatarios (la norma equiparadora) no siempre preserva la igualdad formal. El mandato de igualdad ante la ley — se ha dicho ya- no proscribe la discriminación por indiferenciación. Sin embargo, es posible que una norma que no hace diferencia alguna entre individuos — sino en rasgos atribuibles a clases de individuos_- pese a su aparente neutralidad, pueda resultar discriminatoria en sí misma o en su aplicación, si, confrontada con realidades de facto diversas, depara diferenciaciones de trato incompatibles con los criterios expresamente tasados en el artículo 14 CE. La prohibición de toda discriminación indirecta — doctrina consolidada por la jurisprudencia constitucional— ${ }^{5}$,

dad" propia de las minorías, cabría preguntar qué quedaría de la que en democracia, y previa deliberación pública, la mayoría adopta para todos», Jiménez CAMPo, J. (2017), «Acotaciones sumarias sobre el "derecho a la diferencia" de trato», en Asociación de letrados del Tribunal Constitucional (Ed.), Democracia constitucional y diversidad cultural, Centro de Estudios Políticos y Constitucionales, pp. 26 y 27. Sobre esta problemática véase las SSTC 38/2014; 86/1985.

${ }^{3}$ STC 63/2011.

${ }^{4}$ Sobre la exigencia de generalidad de la Ley véase García De EnTERría, E. (1986). Revolución francesa y administración contemporánea y formación del sistema municipal francés contemporáneo, Madrid, Taurus, pp. 17-20; GAVARA DE CARA, J. C. (2005). Contenido y función del término de comparación en la aplicación del principio de igualdad, Cizur Menor, Aranzadi, pp. 23-141; Villacorta Mancebo, L. (2005). «Principio de igualdad y legislador: arbitrariedad y proporcionalidad como límites (probablemente insuficientes)». Revista de Estudios Políticos, n. ${ }^{\circ} 130$, octubre-diciembre, p. 69.

5 SSTC162/2016; 66/2014. 
puede redundar en un derecho al reconocimiento de la igualdad de trato en favor de los grupos nominalmente relacionados en el artículo $14 \mathrm{CE}^{6}$.

El mandato de igualdad de trato proscribe toda discriminación por razón de sexo, pues ser mujer o las diferencias de roles socialmente atribuidas al grupo de población femenino — el género- nunca puede ser objeto de diferencias en el contenido de la ley (discriminación directa).

Así mismo, la norma puede ser contraria a la igualdad de trato del artículo $14 \mathrm{CE}$ cuando, pese a su aparente neutralidad, su aplicación redunda en un perjuicio para las mujeres que convierte la sospecha de discriminación en certeza (discriminación indirecta).

La igualdad de trato proscribe toda diferencia por razones ad personam, entre ellas el sexo; sin embargo, en el Estado social español es posible que la ley establezca diferencias entre individuos o grupos, cuando éstos son desiguales en oportunidades o son perjudicados en ámbitos concretos de la vida presente (art. 9.2 CE). Si el mandato del artículo $14 \mathrm{CE}$ exige que el legislador identifique a los individuos por la objetividad del rasgo jurídico que los equipara, el mandato contenido en el artículo 9.2 CE exige que el legislador identifique a los individuos o a los grupos (las mujeres) por la diferencia que los perjudica o los hace desiguales en oportunidades en un ámbito de la realidad social presente.

La exigencia de igualdad real y efectiva entre mujeres y hombres ha trascendido a la implementación de medidas de acción positiva para las mujeres en la medida en que resultan perjudicadas frente a los hombres o no son iguales en oportunidades en ámbitos de la realidad social presente. Tales medidas están destinadas a corregir «situaciones patentes de desigualdad de hecho» respecto de los hombres y serán aplicables en tanto subsistan dichas situaciones. También habrán de ser razonables y proporcionadas (art. 11.1 de la LO 3/2007, de 22 de marzo, para la igualdad efectiva de mujeres y hombres, en adelante, LOI).

La doctrina ha puesto el acento en la consideración de las mujeres como grupo minusvalorado socialmente, al definir las acciones positivas como los tratos formalmente desiguales que favorecen a determinados grupos que a diferencia de los individuos se caracterizan por poseer un rasgo diferenciador en común que es minusvalorado socialmente (el sexo o la raza) y que la Constitución menciona como cláusula específica de no discriminación ${ }^{7}$. De entre ellas, distingue las acciones positivas moderadas de las medidas de discriminación inversa. Si

6 Jiménez Campo, J., Acotaciones..., ob. cit., pp. 21-22.

A diferencia de las medidas de acción positiva, las medidas de igualación positiva son definidas como los tratos formalmente desiguales que tienen por finalidad constitucionalmente admisible la igualdad entre los ciudadanos individualmente considerados, en relación con su situación de inferioridad, Giménez Gluck, D. (1999). Una manifestación..., ob. cit., p. 58. 
bien las primeras tratan de remover los obstáculos que impiden a los miembros de estos grupos minusvalorados socialmente llegar al proceso selectivo en igualdad de condiciones, las medidas de discriminación inversa son concretas acciones positivas consistentes en reservar cuotas a determinados grupos minusvalorados en los procesos selectivos para acceder a bienes escasos en la sociedad ${ }^{8}$. El perjuicio que la medida supone para quienes no quedan beneficiados por ella se justifica en la consideración de las mujeres como grupo de población socialmente minusvalorado cuyo rasgo —el sexo- está expresamente reconocido en la Constitución; también se reconoce que en la medida en que la discriminación inversa provoca perjuicios a otros posibles beneficiarios de un bien escaso se somete a un control más estricto de constitucionalidad.

Las acciones positivas moderadas son acordes artículo 9.2 CE pues la remoción de los obstáculos para que las mujeres sean iguales que los hombres en el punto de partida del proceso selectivo se relaciona con una variabilidad de situaciones colaterales en las que las mujeres siguen siendo diferentes en oportunidades a los hombres. Las medidas de discriminación inversa, consistentes en cuotas para mujeres en procesos selectivos, obviando la objetivación en el mérito y la capacidad, resultan difícilmente conciliables con las exigencias de la igualdad formal.

La perseguida igualdad real y efectiva de mujeres y hombres en el acceso y permanencia en el empleo puede armonizarse con la exigencia formal de la igualdad (establecimiento de diferencias conforme al mérito y capacidad) estableciendo otras políticas antidiscriminatorias que no supongan un perjuicio a otros posibles beneficiarios del bien que acrediten superioridad en el mérito. Así, por ejemplo, resulta difícilmente acorde con la igualdad de trato incluir cuotas para las mujeres en los procesos selectivos de contratación privada. Sin embargo, es conforme con las exigencias de los artículos 9.2 y $14 \mathrm{CE}$ instar a los poderes privados a objetivar los criterios de mérito y capacidad (intelectuales y emocionales) en los procesos selectivos de acceso y permanencia en el empleo. También son acordes con los artículos 14 y 9.2 CE las medidas de acción positiva consistentes en ayudas económicas que incentiven la iniciativa empresarial de las mujeres — en mayor medida que la de los hombres — con base en un análisis de las menores oportunidades de las mujeres en un concreto sector. Así por ejemplo, subvencionar en mayor medida la iniciativa de las mujeres jóvenes que quieran ser titulares de una explotación agraria frente a la de los hombres jóvenes que persigan igual iniciativa con base en la menor incidencia de las mujeres en este sector constatable en datos (menor cantidad de mujeres registrada en el registro

\footnotetext{
${ }^{8}$ Giménez Gluck, D. (1999). Una manifestación..., ob. cit., pp. 76-82.
} 
general de la producción agrícola), y la verificación de que las mujeres trabajan la tierra pero son invisibles como titulares de la explotación agrícola frente a los hombres.

También son acordes con las exigencias de los artículos 14 y 9.2 CE las medidas de acción positiva consistentes en cuotas para mujeres (mayoría de mujeres en las listas que presenten los partidos) o en porcentajes de hombres y mujeres en el resultado de los procesos selectivos de candidatos elegidos por los partidos políticos. La razón estriba en que tales procesos consistentes en la selección de los que mejor pueden desempeñar el cargo por los partidos políticos no siguen procesos objetivos de mérito y capacidad, por lo que no suponen una vulneración del artículo $14 \mathrm{CE}$; dicho de otra manera, no existen pruebas objetivas de méritos que valoren las aptitudes racionales y emocionales para ser un buen político, lo que impediría que se pudieran establecer porcentajes de hombres y mujeres; el mérito de los candidatos se presupone, en aras de conseguir escaños, pero no se objetiva. En este sentido, no se puede argüir que las cuotas cercenan el derecho fundamental de sufragio pasivo del varón preterido (vulneración de la igualdad formal); tampoco se puede alegar que las cuotas obligan a buscar mujeres sospechosamente «menos meritorias» que los hombres, pues la misma suposición de ausencia de mérito se podría predicar de los hombres.

La imposición de porcentajes de mujeres y hombres en las listas fundada en que, en la vida real, la elección de candidatas femeninas es mucho menor que la de los hombres resulta conforme con el artículo 9.2 CE. La medida de acción positiva consistente en exigir mayores porcentajes de mujeres en las listas (al menos el $51 \%$ o incluso posibilidad de listas conformadas por mujeres) también es acorde con el artículo 9.2 CE pero se vincula a la exigencia de evaluación temporal de los resultados que se pretenden: la democracia paritaria-; de tal forma que, una vez conseguido el objetivo de la paridad, la medida de acción positiva debe convertirse en una medida antidiscriminatoria, o, incluso, en una medida formalmente neutra, si la cultura social acaba asumiendo que las listas tienen que ser paritarias aunque la ley no lo imponga.

Alejándose del debate en torno a si es la igualdad formal o la igualdad material la que debe imperar en el ámbito de la participación política, la doctrina ha avalado tales medidas desde la legitimidad del sistema democrático del Estado entendiendo que «la democracia rectamente entendida no puede ser sino democracia paritaria» porque «la democracia paritaria se muestra como una cuestión 
de legitimidad democrática que surge como tal con la evolución del Estado liberal hacia el Estado democrático? .

Tanto desde esta perspectiva como desde la armonización de los artículos 14 y 9.2 CE es posible la defensa de la democracia paritaria. Tales listas, además, no solo deben asegurar una composición paritaria por cada tramo de cinco puestos: es preciso exigir una alternancia de sexos en cada tramo (listas cremallera), con el fin de garantizar que la presencia de mujeres en los órganos de decisión quede, en realidad, al albur del número de escaños obtenidos por los partidos políticos. Por las mismas razones anteriormente expresadas, tales porcentajes de mujeres y hombres no solo deben ser exigibles en las listas que presentan los partidos políticos; también tienen que ser preceptivos para todos los órganos del Estado cuya elección no se base en una objetivación del mérito y la capacidad (mesa y comisiones del parlamento, órganos de gestión de las administraciones, etc.). Sería deseable que tal paridad trascendiera al ámbito privado, en relación con los órganos directivos de las empresas. Sin embargo, tal pretensión debe ser compatible con la libertad empresarial (art. $38 \mathrm{CE}$ ). De modo que es posible establecer incentivos para que las empresas que garanticen una composición paritaria en sus órganos directivos, pero no es posible obligar a las empresas a su cumplimiento (art. 50.4 LOI).

La tensión entre los artículos 14 y 9.2 CE se ha evidenciado con ocasión de los avances científicos que han equiparado a hombres (transgénero) y a mujeres en un rasgo que antes diferenciaba a las mujeres en oportunidades en la vida real (la maternidad). La desaparición de la exclusividad en el rasgo que antes hacía desiguales a las mujeres respecto de los hombres (art. 9.2 CE) convierte la medida de acción positiva en una medida discriminatoria por razón de identidad sexual (art. 14 CE). La razón estriba en que la suspensión del contrato por maternidad para mujeres ya no se justifica en una desigualdad real y efectiva entre hombres y mujeres en ese ámbito vital. La implementación de medidas de acción positiva — exigencia de igualdad real y efectiva entre mujeres y hombres - tiene que armonizarse con el mandato de igualdad de trato o igualdad formal como prohibición de discriminaciones por razones ad personam; significa que es posible implementar medidas de acción positiva en aquellos ámbitos de la realidad social presente en los que las mujeres son desiguales en oportunidades respecto de los hombres o están siendo perjudicadas en la vida real. Pero significa también que

9 Rodríguez Ruiz, B. (2007). «De la paridad, la igualdad y la representación en el Estado democrático». Revista Española de Derecho Constitucional, n. ${ }^{\circ} 81$, p. 143 . Sobre el tránsito del Estado liberal hacia un Estado democrático que incorpora el derecho de sufragio universal masculino y femenino, véase Rodríguez, De la paridad..., ob. cit, pp. 143-151. 
una vez erradicada la diferencia factual que las diferenciaba de los hombres, tal derecho debe ser compartido por quienes se identifican en el rasgo al que la ley otorga relevancia jurídica (los hombres transgénero).

\section{IGUALDAD FORMAL: PROHIBICIÓN DE DISCRIMINACIONES DIRECTAS E INDIRECTAS POR RAZÓN DE SEXO}

A partir de la década de los 90, la jurisprudencia constitucional prohibió toda discriminación directa contenida en normas que diferenciaban a mujeres y a hombres en la consecución de derechos ${ }^{10}$. Se proscribió toda distinción basada únicamente en el sexo, o en la atribución social de roles diferentes a mujeres y a hombres (género) ${ }^{11}$ pues se entendió que las normas no podían otorgar relevan-

10 Aunque la Directiva 79/7/CEE del Consejo (art. 2.1), menciona por primera vez las discriminaciones directas, su definición se contiene en el artículo 2.2 de la Directiva 2002/73/CE, del Parlamento Europeo y del Consejo, de 23 de septiembre de 2002, de modificación de la Directiva 76/207/CEE del Consejo: «la situación en que una disposición, criterio o práctica aparentemente neutros sitúan a personas de un sexo determinado en desventaja particular con respecto a personas del otro sexo, salvo que dicha disposición, criterio o práctica pueda justificarse objetivamente con una finalidad legítima y que los medios para alcanzar dicha finalidad sean adecuados y necesarios». El artículo 6.1 de la LO 3/2007, de 22 de marzo, para la Igualdad Efectiva de Mujeres y Hombres (en adelante, LOI) transpone la definición de discriminación directa por razón de sexo contenida en el artículo 2.1.a de la Directiva 2006/54/CE del Parlamento Europeo y del Consejo, de 5 de julio de 2006, de refundición de las Directivas anteriores relativas a la aplicación del principio de igualdad de oportunidades e igualdad de trato entre hombres y mujeres en asuntos de empleo y ocupación: «Se considera discriminación directa por razón de sexo la situación en que se encuentra una persona que sea, haya sido o pudiera ser tratada, en atención a su sexo, de manera menos favorable que otra en situación comparable».

11 BEAUvorr entiende que los roles de la mujer constituyen un producto cultural construido socialmente; de tal forma que las características que las identifican como tales no se originan de su genética, sino de cómo han sido educadas y socializadas, BEAUvoIr, S. (1978). El segundo sexo, Buenos Aires, siglo xxi; en tal sentido, el sexo/género se define como el conjunto de prácticas, normas, símbolos, representaciones y valores sociales que las sociedades elaboran a partir de la diferencia biológica entre sexos, Rubin, G. Glover, D. Kaplan, C. (2002). Géneres i identitats culturals, Vic, Eumo, p. 34; es expresión de la existencia de una normatividad femenina edificada sobre el sexo como hecho anatómico, Coвo BEdía, R. (2008). «El género en las ciencias sociales», en laurenzo Copello, P. Maqueda Abreu, M. L. Rubio Castro, A. M. (Coords.), Género, violencia y derecho, Valencia, Tirant lo Blanch, p. 53. En opinión de Ventura Franch, «hay dos grandes bloques de funciones en la historia de la humanidad, en la que los hombres, por tener un sexo determinado, han realizado las que tienen más valor, las del dominante, mientras que las mujeres, por tener un sexo diferente al del hombre, han realizado todas aquellas que socialmente tienen un reconocimiento menor. Las diferentes asignaciones de funciones sociales en base al sexo han generado una estructura social marcada por la subordinación y la discriminación de las muje- 
cia jurídica a diferencias — científicamente probadas o supuestamente apreciadas - atribuibles a un individuo o a un grupo en su identidad individual o colectiva $^{12}$.

Todo ello redundó en normas que equipararon en derechos laborales a las mujeres respecto de los hombres ${ }^{13}$; o que, en menor medida, identificaron en derechos económicos y en derechos-deberes de conciliación de la vida personal y familiar a ambos grupos de población. Entendiendo que, en las mismas circunstancias, la concesión de derechos solo para hombres suponía un reconocimiento jurídico de la diferente valoración social de las mujeres contrario al artículo 14 CE; o que la regulación de derechos-deberes de conciliación para los hombres era, en realidad, un paso más en la persecución de la deseada corresponsabilidad en las tareas de cuidado por hombres y mujeres ${ }^{14}$. El mandato de igualdad de

res en todos los ámbitos», Ventura Franch, A. (2016). «El Convenio de Estambul y los sujetos de la violencia de género. El cuestionamiento de la violencia doméstica como categoría jurídica», Revista de Derecho Político. n. ${ }^{\circ}$ 97, septiembre-diciembre, p. 188.

12 Es lo que la doctrina denomina como «discriminación primaria» que se presenta cuando se admite que existe una diferencia previa de valoración de seres humanos, TUGENDHAT, E. (I997). Lecciones de ética, Barcelona, Gedisa 1997, p. 358. La igualdad formal exige vetar toda distinción basada en criterios subjetivos, calificados por la doctrina como sospechosos, entre los que se encuentra el sexo, Rey MARTínez, F. (1995). El derecho fundamental a no ser discriminado por razón de sexo, Madrid, McGraw-Hill, pp. 51-54; Rey MarTínez, F. (2014). «El principio de igualdad en el contexto de la crisis del Estado social: diez problemas actuales». Fundamentos. Cuadernos monográficos de teoría del Estado, derecho público e historia constitucional, n. ${ }^{\circ}$ 8, p. 297.

${ }^{13}$ La jurisprudencia del Tribunal Constitucional declaró contrarias al artículo 14 CE las normas que suspendían el contrato por matrimonio de la mujer trabajadora, pero no por matrimonio del hombre trabajador; también las que prohibían a las mujeres ser aviadoras o trabajar en la mina (SSTC 7/1983; 216/1991; 229/1992). Sobre la evolución de la normativa y la jurisprudencia sobre prohibición de discriminación por razón de sexo, véase Ricoy CASAs, R. M. (2010). ¿Qué igualdad? El principio de igualdad formal y no discriminación por razón de sexo en el ordenamiento jurídico español, Madrid, Dykinson, pp. 325-336.

${ }^{14}$ Se reformaron normas que ignoraban a los hombres en derechos de prestación económica por cuidado de familiares (STC 3/1993), o en derechos-deberes de conciliación (permiso de lactancia artificial solo para mujeres). Si bien en este último caso la modificación normativa no fue precedida por una jurisprudencia constitucional que avalara tal reforma. La STC 109/1993 determinó necesario el mantenimiento de este derecho de conciliación de la vida laboral y familiar para las mujeres por razones históricas de desigualdad en el acceso al empleo del grupo de población femenino; sin embargo, el voto particular del magistrado Vicente Gimeno Sendra advirtió de la importancia de la compartición de las medidas de conciliación entre mujeres y hombres para no ralentizar las oportunidades laborales de aquéllas: «A nadie se le oculta que, para un empresario poco escrupuloso con el principio de igualdad, siempre le será "más rentable" contratar a hombres que a mujeres trabajadoras, dado el incremento de los costes laborales, que, por esta causa y por otras biológicas (vgr: las bajas por maternidad), las mujeres siempre ocasionan». En puridad, la STC 109/1993 siguió considerando la titularidad femenina del permiso de lactancia como una 
trato también repercutió en la proscripción de discriminaciones originadas por el hecho biológico de ser mujer ${ }^{15}$.

La consolidación normativa y jurisprudencial de la prohibición de discriminaciones directas se completó con la proscripción de discriminaciones indirectas, fundamentalmente, en el ámbito laboral ${ }^{16}$. Se entendió, así, que el artículo $14 \mathrm{CE}$ prohíbe la discriminación por indiferenciación en normas aparentemente neutras cuyo demostrado perjuicio para las mujeres convierte la sospecha de discriminación en certeza ${ }^{17}$. En definitiva, se constató que la norma no diferenciado-

medida de acción positiva, en detrimento del principio de igualdad de sexos, LAUSADA AROCHENA, J. F. (2008). Permiso de paternidad y conciliación masculina, Albacete, Bomarzo, p. 75.

${ }_{15}$ Así pues, se proscribió el despido por embarazo ex artículo 14 CE (STC 136/1996), en la línea establecida por la jurisprudencia del TJUE (véase, entre otras, STJCE, de 4 de diciembre de 1997, Asunto Comisión c. República Italiana). El artículo 8 LOI califica como «discriminación directa por razón de sexo todo trato desfavorable a las mujeres relacionado con el embarazo o la maternidad».

${ }^{16}$ Aunque la Directiva 79/7/CEE del Consejo (art. 4), menciona por primera vez las discriminaciones indirectas, su definición se contiene en el artículo 2.2 de la Directiva 2002/73/CE, del Parlamento Europeo y del Consejo, de 23 de septiembre de 2002, de modificación de la Directiva 76/207/CEE del Consejo: «la situación en que una disposición, criterio o práctica aparentemente neutros sitúan a personas de un sexo determinado en desventaja particular con respecto a personas del otro sexo, salvo que dicha disposición, criterio o práctica pueda justificarse objetivamente con una finalidad legítima y que los medios para alcanzar dicha finalidad sean adecuados y necesarios». El artículo 6.2 LOI transpone la definición de discriminación indirecta por razón de sexo contenida en el artículo 2.1.b de la Directiva 2006/54/CE del Parlamento Europeo y del Consejo, de 5 de julio de 2006, de refundición de las Directivas anteriores relativas a la aplicación del principio de igualdad de oportunidades e igualdad de trato entre hombres y mujeres en asuntos de empleo y ocupación: «la situación en que una disposición, criterio o práctica aparentemente neutros pone a personas de un sexo en desventaja particular con respecto a personas del otro, salvo que dicha disposición, criterio o práctica puedan justificarse objetivamente en atención a una finalidad legítima y que los medios para alcanzar dicha finalidad sean necesarios y adecuados».

17 El Tribunal Constitucional consideró discriminación indirecta la diferente retribución asignada al personal de la sección de limpiadoras respecto de la retribución de la sección de peones; idéntico resultado discriminatorio extrajo en relación con la diferente retribución asignada al personal femenino de la sección de envasado y empaquetado de una empresa respecto de la atribuida al personal masculino en la sección de producción. Y si bien las empresas justifican el mayor sueldo de los trabajadores en que el trabajo no es el mismo, el Tribunal Constitucional afirma que la identidad de salario no tiene que ver con la diferencia de trabajo sino con el valor que ese trabajo tiene. Concluye que el valor del trabajo en las distintas secciones es el mismo, y que solo las mujeres trabajan en la sección peor pagada, por lo que considera tal actuación empresarial como discriminación indirecta que conculca el artículo 14 CE (SSTC 145/1991; 286/1994).

La jurisprudencia constitucional también consideró que la denegación del permiso de excedencia a una funcionaria interina que llevaba 5 años trabajando comporta una discriminación indirecta. La norma era aparentemente neutra porque entendía que solo los funcionarios, y no los interinos, podían pedir la excedencia. Sin embargo, la demandante demuestra que la administra- 
ra —aparentemente formal— también podía ser contraria al artículo 14 CE (prohibición de discriminación por indiferenciación) si los resultados de su aplicación eran perjudiciales para las mujeres ${ }^{18}$.

A partir de la década del 2000, la aprobación de normas nacionales ${ }^{19}$ y autonómicas ${ }^{20}$ que regulan políticas públicas en materia de igualdad de género no

ción llevaba varios años sin convocar plazas, la mayoría de los funcionarios interinos era mujeres (STC 240/1999).

${ }^{18}$ La discriminación indirecta se origina del resultado perjudicial que la norma aparentemente neutra genera para un determinado colectivo, con independencia de cuál haya sido la intención del legislador. Ello supone una mayor protección para los colectivos desfavorecidos en la medida en que cualquier norma que tenga un contenido discriminatorio para ellos sería contraria a derecho, con independencia de si hubo intención de perjudicar o no por parte del legislador, Giménez GLUCK, D. (2011). «La legislación y la jurisprudencia de la Unión Europea ante la multidiscriminación», en SERRA CRISTóBAL, R. (Coord.), La discriminación múltiple en los ordenamientos jurídicos español y europeo, Valencia, Tirant lo Blanch, pp. 50-51.

19 La LO 1/2004, de 28 de diciembre, de Medidas de Protección Integral contra la Violencia de Género, recuerda que la violencia de género —el tratamiento discriminatorio hacia las mujeres en el ámbito doméstico y el de las relaciones de pareja con o sin convivencia- se basa en una diferente valoración entre los hombres y las mujeres, al tratase de una violencia dirigida a las mujeres por el hecho de serlo, por ser consideradas por sus agresores carentes de los derechos mínimos de libertad, respeto y capacidad de decisión. Por su parte, la LO 3/2007, de 22 de marzo para la igualdad efectiva de mujeres y hombres ha supuesto norma de transposición de las Directivas de la Unión Europea sobre igualdad entre mujeres y hombres. En este sentido, no solo define las discriminaciones directas e indirectas; también regula las distintas manifestaciones de la discriminación directa (acoso sexual, acoso por razón de sexo, artículo 2 de la Directiva 2002/73/CE del Parlamento Europeo y del Consejo, de 23 de septiembre de 2002, artículo 2 de la Directiva 2004/113/CE por la que se aplica el principio de igualdad de trato entre hombres y mujeres al acceso a bienes y servicios de suministro y artículo 2.1.c y d de la Directiva 2006/54/CE del Parlamento Europeo y del Consejo, de 5 de julio de 2006, relativa a la aplicación del principio de igualdad de oportunidades e igualdad de trato entre hombres y mujeres en asuntos de empleo y ocupación).

${ }^{20}$ En el ámbito autonómico, se han aprobado leyes recientes sobre igualdad: la Ley Catalana 17/2015, de 21 de julio, de igualdad efectiva de mujeres y hombres, la Ley Balear 11/2016, de 28 de julio, de igualdad de mujeres y hombres, o la Ley foral 14/2015, de 10 de abril, para actuar contra la violencia hacia las mujeres. Recientemente, la STC 159/2016 ha anulado varios preceptos de la Ley del Parlamento de Cataluña 17/2015, de 21 de julio, de igualdad efectiva entre mujeres y hombres que incorporan la perspectiva de género en materias de legislación laboral: prevención del acoso sexual en las empresas, planes de igualdad en las empresas, responsables sindicales de igualdad, presencia de mujeres y hombres en la negociación colectiva, incorporación de la perspectiva de género en los expedientes de regulación de empleo y prevención de riesgos laborales. El Tribunal Constitucional expresa que si bien el artículo 153 del Estatuto de Autonomía Catalán tiene competencia exclusiva sobre competencias de género, estas no pueden incidir en material laboral por ser ésta competencia exclusiva del Estado ex artículo 149.1.7. ${ }^{a} \mathrm{CE}$ : «La materia política de género se proyecta de un modo genérico sobre todas las materias reguladas en 
ha impedido la persistencia de actuaciones — más que de normas — que discriminan mayoritariamente a las mujeres de manera directa ${ }^{21}$. En el ámbito penal se ha evidenciado que las diversas manifestaciones de la violencia — especialmente, la intrafamiliar y de relaciones de pareja, con o sin convivencia-, suponen una discriminación para las mujeres, en la medida en que el grupo de población femenino es mayormente víctima de estas agresiones contrarias a la igual dignidad de ser humano ${ }^{22}$.

En el ámbito laboral se ha regulado el acoso sexual ${ }^{23}$ y el acoso por razón de sexo, como manifestaciones de la violencia en el trabajo, mayormente ejercidas contra las mujeres ${ }^{24}$. Los planes de igualdad que algunas empresas están obliga-

la Ley de igualdad pero si existe un título específico que atribuye al Estado o a la Comunidad Autónoma competencia sobre una determinada materia, la competencia sobre política de género pasa a un segundo plano pues, de lo contrario, quedaría desbordado el ámbito y sentido de este título competencial que no puede operar como un título capaz de introducirse en cualquier materia o sector del ordenamiento. El legislador autonómico puede dictar medidas relativas al título competencial de políticas de género en caso de que afecten a sectores sobre los que tenga competencia».

${ }_{21}$ Así, por ejemplo, los despidos por embarazo siguen siendo, a día de hoy, práctica que el Tribunal Constitucional ha considerado discriminatoria por razón de sexo (SSTC 124/2009; 92/2008 y 136/1996), salvo que la trabajadora se encuentre en tiempo de prueba (STC 173/2013). Más recientemente, el Tribunal Constitucional ha considerado discriminatoria por razón de sexo, no reconocer derechos económicos y administrativos a una funcionaria con carácter retroactivo, desde la finalización del curso de acceso a empleo público de sus colegas de promoción (funcionaria en prácticas), y no desde que finaliza el curso de acceso retrasado por parto (STC 66/2014, en la misma línea establecida por la STJUE de 6 de marzo de 2014, asunto Napoli). La normativa de utilización de distinta vestimenta para mujeres y para hombres también ha sido considerada discriminatoria por razón de sexo (STC 84/2006).

${ }^{22}$ Sobre las discriminaciones directas en relación con la igualdad dignidad como especie humana, véase Zoco ZaBALA, C. (2015). «Dignidad e igualdad dignidad en la Constitución Española», en Chueca Rodríguez, R. (Dir.), Dignidad Humana y Derecho Fundamental, Madrid, Centro de Estudios Políticos y Constitucionales, pp. 401-406.

${ }^{23}$ En el ámbito penal el artículo $184 \mathrm{CP}$ solo regula el acoso sexual, como solicitud de favores sexuales en el ámbito laboral, docente o de prestación de servicios, continuada o habitual; también se requiere causación de situación objetiva y gravemente intimidatoria, QUINTERO Olivares, G. (2016). Comentarios a la parte especial de derecho penal, Cizur menor, Aranzadi, pp. 356-362. El acoso por razón de sexo no queda tipificado como delito.

${ }^{24}$ La LOI ha definido el acoso sexual y el acoso por razón de sexo. El acoso sexual se define como «cualquier comportamiento, verbal o físico, de naturaleza sexual que tenga el propósito o produzca el efecto de atentar contra la dignidad de una persona, en particular cuando se crea un entorno intimidatorio, degradante u ofensivo» (art. 7.1 LOI). El acoso por razón de sexo se define como «La situación en que se produce un comportamiento no deseado relacionado con el sexo de una persona con el propósito o el efecto de atentar contra la dignidad de la persona y de crear un entorno intimidatorio, hostil, degradante, humillante u ofensivo» (art. 7.2 LOI). La doctrina ha 
das a implementar incluyen medidas preventivas del acoso sexual y el acoso por razón de sexo en el trabajo ${ }^{25}$. Sin embargo, tales planes de igualdad han sido criticados en la medida en que se relega la igualdad frente a temas retributivos, la clasificación profesional o el acceso al empleo, o se repiten los mismos esquemas que aparecen enunciados en el tenor literal de la ley ${ }^{26}$. Transcurridos 10 años de la aprobación de la LOI es preciso verificar cuáles han sido los procedimientos que se han llevado a cabo para erradicar las discriminaciones por razón de sexo y los resultados obtenidos

En el ámbito educativo, la inadmisión de estudiantes por razón de sexo en los centros educativos financiados con fondos públicos ha sido debatida por suponer una discriminación directa por razón de sexo no fundada en razones objetivas (art. $14 \mathrm{CE}$ ). La problemática sobre la educación segregada por sexos va más allá de la inadmisión según el sexo; supone el comienzo de la no educación en igualdad por iniciar su apertura a la sociedad en grupos separados y diferenciados. Es preciso formar en la igualdad real y efectiva de hombres y

determinado la importancia de la prevención del acoso sexual y por razón de sexo. Pues tales procedimientos previos son más fáciles en la medida en que no se persigue encontrar un posible culpable, como prevenir las situaciones de acoso y violencia en el trabajo, Mellado, C. L. FÁBregat Monfort, G. Salcedo Beltrán, C. «A modo de introducción. El tratamiento tradicional del acoso», en Fabregat Monfort, G. (Dir.). (2012). Acoso moral, sexual y por razón de sexo en el trabajo: un tratamiento integral, Albacete, Bomarzo, p. 15. Sobre el concepto de acoso sexual y acoso por razón de sexo, véase Fabregat Monfort, G. (2012). «Marco normativo del acoso y perspectiva de género», en Fabregat Monfort, G. (Dir.). Acoso moral, sexual y por razón de sexo en el trabajo: un tratamiento integral, Albacete, Bomarzo, pp. 24-30.

${ }^{25}$ La importancia de estos planes ha redundado en su implementación no solo por las empresas que están legalmente obligadas sino también progresivamente por aquéllas que no lo están. Son empresas obligadas aquéllas de más de 250 trabajadores (obligación legal cuantitativa: art. $45.2 \mathrm{LOI}$ ), las que están incursas en un procedimiento sancionador, cuando la autoridad laboral haya acordado la sustitución del resto de sanciones complementarias por la elaboración de dicho plan (obligación legal cualitativa: art. 45.4 LOI); y, finalmente, las empresas cuya obligación de negociar un plan de igualdad derive de la previsión del convenio en ese sentido (obligación convencional: art. 45.3 LOI). En algunas Comunidades Autónomas como Navarra, el Gobierno ayudó a las empresas que quisieron elaborar planes de igualdad que no cumplían los requisitos de obligada implantación de tales planes. Así pues, se aportó un sistema de trabajo para elaborar - tras una fase de diagnóstico- implantar y evaluar los planes de igualdad en empresas no obligadas ex artículo 45 LOI. En la actualidad es preciso que los resultados de la implementación de tales planes sean evaluados por la administración. El procedimiento IGE (igualdad de género en las empresas de Navarra) se encuentra disponible en la web: https://www.navarra.es/NR/ rdonlyres/5811B2E4-A627-4F31-BCD3-12AE157230CB/197404/MANUALIGE2.pdf (a. 8/06/2017).

${ }^{26}$ López InsúA, B. M. (2017). El principio de igualdad de género en el derecho social del trabajo, Murcia, Laborum, p. 97. 
mujeres $^{27}$; pero, sobre todo, es preciso educar en igualdad, pues así lo exige el ideario democrático-constitucional (art. 27.2 CE).

El debate científico-pedagógico sobre una enseñanza diferenciada por sexos defiende que este método mejora las capacidades de aprendizaje y enseñanza de los alumnos de uno y otro sexo haciendo hincapié en los aspectos jurídicoconstitucionales de la libertad de enseñanza, la libertad de creación de centros docentes o el derecho de los padres a elegir la formación religiosa y moral para sus hijos que esté de acuerdo con sus convicciones ${ }^{28}$; sin embargo, estos argumentos jurídico-constitucionales — señala la doctrina-, quedan delimitados por la necesidad de respetar y perseguir los objetivos del ideario constitucional establecidos en el artículo 27.2 CE entre los que la educación en igualdad de género se encuentra: el pleno desarrollo de la personalidad humana en el respeto a los principios democráticos de convivencia y a los derechos y libertades fundamentales de dicho ideario educativo de la Constitución ${ }^{29}$.

La educación diferenciada por sexos supone una discriminación directa, en la medida en que condiciona la admisión de los estudiantes al sexo de los mismos;

${ }^{27}$ El artículo 27.2 CE determina que «la educación tendrá por objeto el pleno desarrollo de la personalidad humana en el respeto a los principios democráticos de convivencia y a los derechos y libertades fundamentales». Más allá de esta genérica afirmación del artículo 27.2 CE, la Ley Orgánica 8/2013, de 9 de diciembre, para la mejora de la calidad educativa (LOMCE) por la que se modifica el artículo 1.b de la LO 2/2006, de 3 de mayo, de Educación (LOE) establece como objetivo de la educación «La equidad, que garantice la igualdad de oportunidades para el pleno desarrollo de la personalidad a través de la educación, la inclusión educativa, la igualdad de derechos y oportunidades que ayuden a superar cualquier discriminación y la accesibilidad universal a la educación, y que actúe como elemento compensador de las desigualdades personales, culturales, económicas y sociales, con especial atención a las que se deriven de cualquier tipo de discapacidad». Así mismo, el artículo 1.h LOMCE establece que «El desarrollo, en la escuela, de los valores que fomenten la igualdad efectiva entre hombres y mujeres, así como la prevención de la violencia de género» constituyen principios y fines de la educación.

${ }^{28}$ Sobre estos motivos para la defensa de una educación diferenciada, véase Calvo CHARRO, M. (2007). «Apoyo de la jurisprudencia española a la educación diferenciada como una opción legítima dentro de la libertad de elección de centros docentes de los padres». La Ley, n. ${ }^{\circ}$ 6711, pp. 4-8. Sobre la tendencia de los centros educativos extranjeros a desagregar por sexo en aras de una mejora de la calidad de la enseñanza, véase Calvo Charro, M. (2005). «El derecho a una educación diferenciada». Nueva Revista, n. ${ }^{\circ}$ 97, http://www.nuevarevista.net/articulos/el-derechouna-educacion-diferenciada (a. 8/06/2017).

29 Aláez CORRAL, B. (2009). «El ideario educativo constitucional como fundamento de la exclusión de la educación diferenciada por razón de sexo de la financiación pública». Revista Espanola de Derecho Constitucional, n. ${ }^{\circ} 86$, mayo-agosto, p. 39. 
pero sobre todo es contraria al objetivo de instruir y educar en igualdad conforme a objetivos del ideario constitucional que se derivan del artículo $27.2 \mathrm{CE}^{30}$.

La disconformidad de una educación segregada por sexos con el ideario educativo establecido en la Constitución es fundamento para que los centros queden condicionados a la financiación pública (sean concertados) en función de que la enseñanza sea mixta. Cierto, que el artículo 27.9 CE remite a la ley las condiciones que los centros docentes deben reunir para poder obtener financiación pública. Sin embargo, tales requisitos de configuración legal tienen que estar condicionados al cumplimiento de las exigencias constitucionales del ideario educativo establecidas en el artículo $27.2 \mathrm{CE}^{31}$.

El antiguo artículo 84.3 de la LO 2/2006 de 3 de mayo, de Educación (en adelante, LOE) prohibió toda discriminación por razón de sexo en la admisión de estudiantes en centros públicos y privados concertados, al tiempo que instó a la administración a garantizar una educación y acceso en condiciones de igualdad. Este artículo fue modificado por la LO 8/2013, de 9 de diciembre, para la Mejora de la Calidad Educativa (en adelante, LOMCE) con el fin de prohibir, de forma expresa, trato desfavorable a los centros diferenciados por sexos que desean suscribir conciertos con las administraciones educativas (art. 84.3 LOMCE). Y si bien al amparo del antiguo artículo 84.3 LOE la jurisprudencia del Tribunal Supremo estableció que la diferenciación por sexos era contraria al artícu-

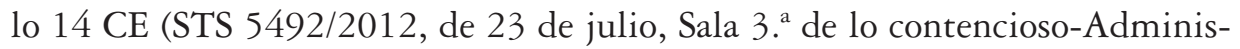
trativo) con arreglo al nuevo artículo 84.3 LOMCE - recurrido en inconstitucionalidad por el grupo parlamentario socialista y por el Consejo de

30 «Sólo la coeducación garantiza adecuadamente que los alumnos de ambos sexos se vean confrontados con la convivencia y conflictos sexuales cotidianos y aprendan "en vivo" a solucionarlos de forma democrática y adecuada», AlÁEz Corral, B. (2009). «El ideario educativo constitucional como fundamento de la exclusión de la educación diferenciada por razón de sexo de la financiación pública». Revista Española de Derecho Constitucional, n. ${ }^{\circ}$ 86, mayo-agosto, p. 59. SAlazAr Benítez, O. (2016). «Educación diferenciada por razón de sexo y derecho a la educación. Sobre la inconstitucionalidad de la reforma del artículo 84.3 de la LOE», Revista Española de Derecho Constitucional, n. ${ }^{\circ} 106$, enero-abril, p. 452.

31 «Dado que el derecho a la educación es (...) el único derecho fundamental ordenado al cumplimiento de una finalidad, más justificado constitucionalmente aún si cabe se encuentra el indirizzo político del legislador para determinar que solo puedan recibir financiación pública los centros escolares que sirvan en un determinado grado al cumplimiento del ideario constitucional, tal y como lo interprete el legislador orgánico, siempre que ello no sea arbitrario o irrazonable», Aláez Corral, B. (2009). «El ideario educativo constitucional como fundamento de la exclusión de la educación diferenciada por razón de sexo de la financiación pública». Revista Española de Derecho Constitucional, n. ${ }^{\circ} 86$, mayo-agosto, p. 54. 
Gobierno de Andalucía ${ }^{32}$ — el Tribunal Supremo ha señalado (STS n. ${ }^{\circ}$ 749/2017, de 5 de mayo de 2017, Sala de lo contencioso-Administrativo, Sección 4. ${ }^{a}$ ) que no se puede asociar la enseñanza segregada por sexos a la discriminación por razón de sexo, pues los estudiantes de ambos sexos reciben enseñanzas con idénticas asignaturas. Así mismo, resuelve en sentido contrario a la doctrina constitucional al señalar que la enseñanza mixta «es un medio, no el único, de promover la eliminación de aspectos de la desigualdad por razón de sexo» ${ }^{33}$.

Hace unos años se ha venido incorporando al debate doctrinal español la problemática de las mujeres que sufren discriminaciones múltiples. La discriminación interseccional es aquella situación que se produce cuando una persona sufre discriminación por diversos motivos; ello supone que es tratada de forma menos favorable de lo que hubiera sido otra en su misma situación. Así, por ejemplo, es posible que una persona sea rechazada en un trabajo por ser mujer y por ser inmigrante.

La doctrina norteamericana de los años 80 determinó que la normativa antidiscriminatoria tiende a definir la discriminación en términos de raza o sexo; de tal forma que el paradigma de la discriminación por sexo suele partir de la experiencia de la mujer blanca y el modelo de discriminación por raza suele basarse en la experiencia de los negros más privilegiados, de tal manera que la mujer

32 Recurso de inconstitucionalidad n. $1406-2014$, promovido por más de 50 diputados del partido socialista, http://www.boe.es/buscar/doc.php?id=BOE-A-2014-4051 (a. 8/06/2017); recurso de inconstitucionalidad n. ${ }^{\circ}$ 1455-2014, promovido por el Consejo de Gobierno de Andalucía, http://www.boe.es/buscar/doc.php?id=BOE-A-2014-4057 (a. 8/06/2017). Sobre la vulneración de los artículos 14 y 27.2 CE del nuevo artículo 84.3 LOMCE véase SALAzAR Benítez, O. (2016). «Educación diferenciada por razón de sexo y derecho a la educación. Sobre la inconstitucionalidad de la reforma del artículo 84.3 de la LOE», Revista Española de Derecho Constitucional, n. ${ }^{\circ} 106$, enero-abril, pp. 460-467.

33 Mediante SSTC 234/2015 y 250/2015 el Tribunal Constitucional ha inadmitido dos cuestiones de inconstitucionalidad por incorrecto razonamiento del juicio de relevancia. En ellas el juez cuestiona la inconstitucionalidad del artículo 17.8 de la Ley de presupuestos de Andalucía por entender que la financiación presupuestada para centros diferenciados por sexos, entre otros criterios, vulnera el artículo 81.1 CE, al ser materia atribuida a las leyes reguladoras de derechos fundamentales. El Tribunal Constitucional inadmite ambas cuestiones por entender que el órgano judicial no ha tenido en cuenta lo dispuesto en la disposición transitoria segunda de la Ley Orgánica 8/2013, de 9 de diciembre, para la mejora de la calidad educativa (LOMCE), en relación con la aplicación temporal de la redacción dada al artículo 84.3 de la Ley Orgánica 2/2006, de 3 de mayo, de educación (LOE), por el artículo único.71 LOMCE. Conforme a esta disposición transitoria, «los centros privados a los que en 2013 se les haya denegado la renovación del concierto educativo o reducido las unidades escolares concertadas por el único motivo de ofrecer educación diferenciada por sexos podrán solicitar que se les aplique lo indicado en el artículo 84.3 de esta Ley Orgánica para el resto del actual período de conciertos en el plazo de dos meses desde su entrada en vigor». 
negra solo será protegida frente a la discriminación cuando su realidad coincida con la de las mujeres blancas o la de los hombres negros; sin embargo, en caso contrario, la mujer negra queda desprotegida por cuanto la normativa no contempla que pueda existir una discriminación nueva provocada por la interacción de la raza y el sexo de la que surge una experiencia discriminatoria nueva y diferente ${ }^{34}$.

La coexistencia de la discriminación por razón de sexo con otras discriminaciones ad personam ha consagrado una nueva discriminación interseccional cualitativamente diferente a la suma de todas las discriminaciones por separado que justifica, por tanto, una respuesta diferente ${ }^{35}$. En el caso de las mujeres el problema es mayor porque a las discriminaciones por razón de pertenencia a una raza o por ser persona con capacidad modificada judicialmente se une la que resulta de la minusvaloración social del grupo de población femenino.

La normativa europea que a partir del año 2000 empezó a regular otras discriminaciones diferentes a las del hecho de ser mujer, no ha desarrollado en un único documento la discriminación interseccional como discriminación cualitativamente diferente ${ }^{36}$.

${ }^{34}$ Crenshaw, K., «Demarginalizing the Intersection of Race and Sex: a Black Feminist Critique of Antidiscriminaton Doctrine, Feminist Theory and Antiracist Politics», en Wisberg, D. K., Feminist Legal Theory. EUA, Foundations, 1993, pp. 383 y ss. Sobre el tratamiento de la discriminación múltiple en Estados Unidos y en Canadá, véase Rey MarTínez, F. (2008). «La discriminación múltiple. Una realidad antigua, un concepto nuevo». Revista Española de Derecho Constitucional, n. ${ }^{\circ} 84$, pp. 255-263.

${ }_{35}$ Makkonen, diferencia entre discriminación múltiple, interseccional y compuesta. La discriminación múltiple se produce cuando una persona es discriminada por varios motivos pero en momentos diferentes. La discriminación adicional o compuesta se origina cuando se producen varias discriminaciones en la misma persona de forma simultánea pero no actúan de forma conjunta. La discriminación interseccional, sin embargo, se produce cuando la interactuación simultánea de varios motivos de discriminación que se producen de forma simultánea, redunda en una discriminación cualitativa diferente. Multiple, Compound and Intersectional Discrimination: bringing the experiences of the most marginalized to the fore, Turku, Institute For Human Rights, Abo Akademi University, abril, 2002, pp. 9-18. La doctrina considera que la discriminación interseccional responde al intento de conformar una discriminación cualitativamente diferente que garantice una mayor protección a las mujeres que la padecen, GIMÉNEz GLUCK, D. (2011). «La legislación y la jurisprudencia de la Unión Europea ante la multidiscriminación», en SERra CrIstóbal, R. (Coord.), La discriminación múltiple en los ordenamientos jurídicos español y europeo, Valencia, Tirant lo Blanch, p. 59; Rey MARTíneZ, F. (2008). «La discriminación múltiple, una realidad antigua, un concepto nuevo», Revista Española de Derecho Constitucional, n. ${ }^{\circ}$ 84, p. 266.

36 Sobre la evolución de las Directivas Europeas reguladoras de las distintas discriminaciones, véase GIMÉNEZ GLUCK, D. (2011). «La legislación y la jurisprudencia de la Unión Europea ante la multidiscriminación», en SERRA CRISTÓBAL, R. (Coord.), La discriminación múltiple en los ordenamientos jurídicos español y europeo, Valencia, Tirant lo Blanch, pp. 55-60. 
Tampoco la LO 3/2007, de 22 de marzo para la igualdad efectiva de mujeres y hombres (LOI) hace referencia a la discriminación interseccional, si bien el artículo 14.6 LOI hace somera referencia a la necesidad de considerar las singulares dificultades en que se encuentran las mujeres de colectivos de especial vulnerabilidad como son las que pertenecen a minorías, las mujeres migrantes, las niñas, las mujeres con discapacidad, las mujeres mayores, las mujeres viudas y las mujeres víctimas de violencia de género, para las cuales los poderes públicos podrán adoptar, igualmente, medidas de acción positiva.

Las Comunidades Autónomas han dedicado algún artículo a definir la expresión «discriminación múltiple» en leyes que, sin embargo, tienen por objeto erradicar un solo tipo de discriminación (por razón de identidad de género, de identidad sexual, o de orientación sexual). Así pues, la definición de «discriminación múltiple» no ha redundado en una política autonómica que implemente medidas transversales para erradicar esta nueva forma de discriminación; en alguna de estas leyes autonómicas, existe una alusión a los poderes públicos para que adopten medidas en aras de erradicar esta discriminación cualitativamente diferente, especialmente cuando coincide una discriminación por razón de sexo/ género con otra por razón de identidad sexual o de orientación sexual. Sin embargo, no se establece un protocolo común que se pueda seguir para erradicar esta nueva forma de discriminación. En alguna ley se alude, de forma somera, a la necesidad de implementar medidas de acción positiva específicas para eliminar la discriminación por razón de orientación sexual o identidad de género ${ }^{37}$. Incluso, alguna norma alude a la necesidad de que el órgano competente en materia de igualdad pueda promover campañas que contribuyan a erradicar la discriminación intersectorial (art. 7.2 LF 8/2017, de 19 de junio, para la igualdad social

37 Así, por ejemplo, el artículo 3.4 de la Ley 2/2014, de 14 de abril, por la igualdad de trato y la no discriminación de lesbianas, gays, transexuales, bisexuales e intersexuales en Galicia expresa que «existirá discriminación múltiple cuando una persona sea discriminada por razón de su orientación sexual y/o identidad de género conjuntamente con otra causa o causas de discriminación, como edad, religión o creencias, convicción u opinión, sexo, origen racial o étnico, incapacidad, enfermedad, lengua, situación económica o cualquier otra condición o circunstancia personal o social, creando una forma específica de discriminación. La discriminación múltiple, por su propia naturaleza, será objeto de especial atención, y, en particular, aquella en la que concurre la causa de sexo conjuntamente con la de orientación sexual y/o identidad de género, de conformidad con la legislación internacional, europea, estatal y autonómica al efecto». Más recientemente, el artículo 5.n de la Ley Foral de 19 de junio, para la igualdad social de las personas LGTBI, establece que «se produce discriminación múltiple cuando además de discriminación por motivo de orientación sexual, expresión de género e identidad sexual o de género o pertenencia a grupo familiar, una persona sufre conjuntamente discriminación por otro motivo recogido en la legislación europea, estatal o foral». 
de las personas LGTBI). Sin embargo, no se regulan medidas transversales de erradicación de esta discriminación cualitativamente diferente.

La discriminación interseccional debería ser objeto de regulación en una única norma estatal que regule un protocolo único para el reconocimiento y tratamiento conjunto de todas las discriminaciones padecidas por la víctima. También para determinar cuáles son las medidas de acción positiva que resultan de la interacción de todas las discriminaciones. Así mismo, sería necesario que la indemnización por daños y perjuicios acumulable por cada una de las discriminaciones (art. 10 LOI) incluyera una sanción o multa derivada del mayor perjuicio que sufren las personas que la padecen ${ }^{38}$.

Más recientemente, en el ámbito laboral, persisten todavía discriminaciones indirectas derivadas de las condiciones menos favorables en las que las mujeres se encuentran en ámbitos concretos de la realidad social lo que han redundado en la inaplicación o en la derogación de normas; así pues, ser trabajadoras a tiempo parcial ha derivado, en algunos casos, en la negación de la pensión de jubilación ${ }^{39}$.

La doctrina ha puesto el acento en la dimensión doméstica de la ciudadanía y en la necesidad de ahondar en las dinámicas de poder intergrupal que sustentan el sistema sexo/género o la división de roles de masculinidad (ciudadanos activos, racionales, libres, independientes, etc.) y feminidad (mujeres dependientes, irracionales, dependientes, inclinadas al cuidado, etc.). Considera que el Tribunal Constitucional empieza a ahondar en tales dinámicas de poder intergrupal por interpretar que las medidas orientadas a garantizar la conciliación de la vida familiar y laboral tienen una dimensión constitucional que se desprende de la lectura conjunta de los artículos 14 y $39 \mathrm{CE}$, de la obligación de los poderes públicos de proteger la familiar, la maternidad y la filiación, así como de fomentar el cumplimiento de la corresponsabilidad parental y de hacer todo ello en términos coherentes con el principio de igualdad como prohibición de discrimi-

38 De Lama Aymà, A. (2013). «Discriminación múltiple». ADC, T. LXVI, p. 315. La doctrina especifica que «En este momento no existen medidas legales que permitan sancionar conductas discriminatorias que no se den en el ámbito laboral, empresarial o profesional. Y, si bien es cierto que se trata de un ámbito especialmente afectado por las conductas discriminatorias, no debe por ello renunciarse a prevenir este tipo de conductas en otros ámbitos. Ello nos plantea dos opciones: o bien generalizamos las sanciones a toda conducta discriminatoria o bien recurrimos a mecanismos del derecho privado», ibidem, p. 316.

39 El Tribunal Constitucional ha considerado que la norma aparentemente neutra que establecía un tiempo mínimo de cotización para cobrar pensión de jubilación (art. 161.1 LGSS), contiene una discriminación indirecta, pues la necesidad de tal cotización mínima perjudicial a la población femenina que mayormente ha trabajado a tiempo parcial (61/2013; 72/2013; 116/2013 y 117/2013). 
naciones por razón de sexo ${ }^{40}$. Así, por ejemplo, se subraya que la norma que incluye medidas de conciliación para funcionarios y no para interinos de larga duración no solo ha sido considerada por el Tribunal Constitucional discriminatoria por razón de sexo porque la interinidad es atributo de las mujeres en la administración; o porque la petición de la medida con base en el carácter temporal de la interinidad pierde toda justificación razonable donde la interinidad es de larga duración. También con el argumento de que, en la actualidad, las mujeres de forma casi exclusiva solicitan este tipo de excedencias ${ }^{41}$.

Sin embargo, más recientemente, la ausencia de datos que acrediten el perjuicio que una concreta medida causa mayormente a las mujeres ha derivado en una jurisprudencia menos proclive a calificar las sospechas de discriminación en certezas. De nuevo, el criterio para evidenciar la discriminación indirecta no se ha basado en la peor situación general en la que se encuentran las mujeres en ámbito laboral, sino en la ausencia de datos que avalen el mayor perjuicio sufrido por las mujeres en un ámbito concreto de la realidad social presente. Así pues, no se ha considerado discriminación indirecta el diferente tratamiento de las carencias de cotización a los trabajadores a tiempo parcial respecto de los que trabajan a tiempo completo en el momento inmediatamente posterior a las suspensión del contrato laboral; entendiendo que «no hay una conexión automática entre que el sexo femenino sea el que desarrolla más comúnmente su trabajo a tiempo parcial con que sea el que se halla con mayor habitualidad en situaciones en que, por haberse terminado su relación a tiempo parcial y no haber surgido ninguna otra, falta la obligación de cotizar» (STC 110/2015 en la misma línea que la STJUE de 14 de abril de 2015, asunto Cachaldora Fernández).

Ello permite pensar que el Tribunal Constitucional consagra la ratio dedicendi de la posible discriminación indirecta en la constatación de los datos reales que provocan tal perjuicio a las mujeres en un concreto ámbito de la realidad laboral (existencia o no de más mujeres despedidas, ex artículo 9.2 CE) más que en una visión general de la peor situación en la que todavía se encuentran las mujeres en el ámbito laboral.

En realidad, la norma que establece una diferencia en el tratamiento de las bases de cotización entre quienes son trabajadores a tiempo completo (integración de las lagunas de cotización con bases mínimas para el cobro de la pensión de jubilación) y quienes no lo son (sólo cómputo de las bases reales cuando tra-

40 Rodríguez Ruiz, B. (2015). «La dimensión constitucional de la conciliación de la vida familiar y laboral, o de la dimensión doméstica de la ciudadanía. Revista Española de Derecho Constitucional, n. ${ }^{\circ} 103$, pp. 355-356 y 360.

41 Rodríguez Ruiz, B. (2015). La dimensión..., ob. cit., p. 361. 
bajaron a tiempo parcial) vulnera el artículo $14 \mathrm{CE}$ en la medida en que su finalidad —integrar las lagunas de cotización con bases mínimas para el cobro de la pensión de jubilación — no incluye a todos sus destinatarios — trabajadores a tiempo completo y a tiempo parcial- (art. $14 \mathrm{CE}$ ). La razón estriba en que dicha norma no cumple las exigencias de proporcionalidad que derivan de toda distinción razonable, pues no integra la base mínima en los periodos de carencia de cotización en proporción a lo trabajado, sino que ignora a quienes trabajan a tiempo parcial en el reconocimiento de este derecho. La declaración de inconstitucionalidad de esta ley por vulneración de la exigencia de proporcionalidad de la medida (art. $14 \mathrm{CE}$ ) tanto para hombres como para mujeres hubiera supuesto, sin duda, un beneficio indirecto para las mujeres despedidas.

\section{IGUALDAD MATERIAL}

Las desigualdades reales y efectivas entre mujeres y hombres que todavía persisten en muchos ámbitos de la realidad social presente han redundado en la implementación de diferentes políticas activas que han perseguido erradicarlas. Desde medidas de acción positiva que otorgan derechos a las mujeres cuando éstas son desiguales en oportunidades en ámbitos concretos de la vida real, hasta medidas represivas con perspectiva de género que persiguen prevenir y eliminar la violencia que sufren las mujeres por su diferente valoración social como seres humanos. La exigencia de igualdad real entre mujeres y hombres también ha repercutido en medidas antidiscriminatorias, que se proyectan en normas que no suponen una excepción al artículo 14.1 CE desde la perspectiva de la naturaleza de la norma; sin embargo, persiguen una igualdad real y efectiva de mujeres y hombres en ámbitos en los que las mujeres son víctimas de discriminaciones indirectas imponiendo iguales o parecidos porcentajes de hombres y mujeres en la consecución de derechos.

Si bien algunas de estas políticas han conseguido garantizar mayores cotas de igualdad real entre ambos grupos de población (medidas antidiscriminatorias en aras de la paridad democrática), otras medidas siguen sin lograr el objetivo de eliminar las discriminaciones de las mujeres o de garantizar una igualdad real y efectiva entre mujeres y hombres (la violencia de género).

\subsection{Medidas de acción positiva}

La existencia de discriminaciones entre mujeres y hombres, o la diferente valoración de las mujeres en su identidad individual o colectiva, ha redundado 
en la implementación de medidas de acción positiva con la finalidad de erradicar o disminuir las diferencias que existen entre ambos grupos de población en ámbitos concretos de la realidad social presente (art. 9.2 CE) ${ }^{42}$. Las medidas de acción positiva otorgan derechos a las mujeres por ser éstas desiguales en oportunidades en ámbitos concretos de la vida real ${ }^{43}$.

En los albores del Estado constitucional se establecieron medidas de acción positiva consistentes en derechos laborales para mujeres justificadas en diferencias biológicas respecto de los hombres que, por ello, las hacía desiguales en oportunidades en la vida laboral (permiso de lactancia natural y suspensión del contrato por maternidad).

Progresivamente, los hombres y las mujeres han sido equiparados en derechos de conciliación de la vida laboral y familiar en la medida en que han podido ser solicitados indistintamente por hombres o por mujeres; así pues, la redistribución de la jornada horaria, las excedencias por cuidado de hijo o de familiar, o la reducción de jornada, por poner algunos ejemplos, son derechos de conciliación que hombres y mujeres pueden demandar indistintamente.

Verdaderamente, estas medidas han perseguido la conciliación de la vida laboral y familiar pero no han tenido por finalidad garantizar la corresponsabilidad real y efectiva en las tareas de cuidado entre progenitores. La práctica ha

42 Como señala Rey MARTíneZ «(...) la prohibición de discriminación específica (por género, raza, etc.) tiene por contenido la igualdad de trato, esto es, la prohibición de las discriminaciones directas o de trato e indirectas o de impacto, y la igualdad de oportunidades, es decir, el mandato de acciones positivas», ReY Martínez, F. (2014). «El principio de igualdad en el contexto de la crisis del Estado social: diez problemas actuales». Fundamentos. Cuadernos monográficos de teoría del estado, derecho público e historia constitucional, n. ${ }^{\circ}$ 8, p. 296.

43 La Directiva 76/207/CEE del Consejo, de 9 de febrero de 1976, relativa a la aplicación del principio de igualdad de trato entre hombres y mujeres, en lo que se refiere al acceso al empleo, a la formación y a la promoción profesionales, y a las condiciones de trabajo insta a la incoación de políticas activas para garantizar la igualdad real y efectiva de hombres y mujeres en la vida laboral. El artículo 3 de la Directiva de refundición 2006/54/CE del Parlamento Europeo y del Consejo, de 5 de julio de 2006, relativa a la aplicación del principio de igualdad de oportunidades e igualdad de trato entre hombres y mujeres en asuntos de empleo y ocupación determina que «los Estados miembros podrán mantener o adoptar las medidas indicadas en el artículo 141, apartado 4 , del Tratado con objeto de garantizar en la práctica la plena igualdad entre hombres y mujeres en la vida laboral». En la línea seguida por la Unión Europea, el artículo 11 LOI ha determinado que «con el fin de hacer efectivo el derecho constitucional de la igualdad, los poderes públicos adoptarán medidas específicas en favor de las mujeres para corregir situaciones patentes de desigualdad de hecho respecto de los hombres. Tales medidas, que serán aplicables en tanto subsistan dichas situaciones, habrán de ser razonables y proporcionadas en relación con el objetivo perseguido en cada caso». 
confirmado que su solicitud ha sido mayoritariamente femenina ${ }^{44}$; en unos casos por las peores condiciones laborales en las que se encuentran las mujeres, lo que favorece que sean ellas quienes soliciten las medidas de conciliación por resultar un menor perjuicio económico familiar; y, en otros, porque siguen pesando los hábitos culturales sobre la mayor responsabilidad de la mujer en las labores de cuidado, incluso, cuando hombres y mujeres asumen trabajos de igual o equivalente categoría.

Con el objetivo de impulsar una mayor demanda masculina de los derechos de conciliación algunas Comunidades Autónomas regularon medidas de acción positiva para hombres consistentes en ayudas para los progenitores masculinos que hubieran solicitado una excedencia por cuidado de hijos ${ }^{45}$; sin embargo, tales fórmulas no han conseguido el objetivo de igualdad en la corresponsabilidad. No tanto porque los hombres no hayan adquirido mayor conciencia sobre la corresponsabilidad en las tareas de cuidado ${ }^{46}$, sino porque la decisión sobre quién

44 A partir de 2013, la jurisprudencia ha adoptado una posición más favorable a la compartición del derecho del lactancia para funcionarios - y por analogía para los contratados laboralesque anteriormente solo podía ser ejercido con exclusividad por uno de los progenitores, adoptando una interpretación del enunciado (art. 48.1.f EBEP) bajo la máxima de Kelsen de que «lo que no está expresamente prohibido está permitido». La Sección 5. a de la Sala de lo ContenciosoAdministrativo de la Audiencia Nacional, mediante sentencia de 30 de octubre de 2013, determina que la prohibición de que los funcionarios públicos pudieran compartir el permiso de lactancia, de forma sucesiva hasta los doce meses (art. 48.1.f) de la Ley 7/2007 de 12 abril 2007 del Estatuto Básico del Empleado Público ) se había basado en una interpretación restrictiva del precepto que hacía la administración del artículo 48.1f EBEP in fine: «Este derecho podrá ser ejercido indistintamente por uno u otro de los progenitores, en el caso de que ambos trabajen». Se interpreta que la administración pretende «restringir o limitar aquello que la norma jurídica no contiene en su dicción (....). Y se determina que la solicitud de compartición de tal permiso suponía el compromiso y la asunción por ambos progenitores de su implicación personal e individual en la atención y cuidado del lactante. Ello debe aplicarse por analogía al personal laboral. Sobre el permiso de lactancia como permiso por cuidado de hijos/as por los progenitores, véase Lousada Arochena, J. F. (2010). «El permiso de lactancia es un permiso para el cuidado de hijos/as». Diario La Ley, n. ${ }^{\circ}$ 7536, 28 de diciembre de 2010, Año XXXI, p. 1.

${ }_{45}$ Así, por ejemplo, mediante Orden Foral 234/2012, de 22 de mayo, de la Consejera de Política Social, igualdad, deporte y juventud, se aprobó una convocatoria de ayudas para fomentar la corresponsabilidad familiar en el cuidado de hijos e hijas, para padres que durante el año 2011 hubieran disfrutado de una excedencia para el cuidado de sus hijos e hijas con una cantidad de 600 euros.

${ }^{46}$ La doctrina ha defendido la progresiva concienciación masculina de los roles de cuidado: «En cuanto a la inteligencia emocional por parte de los hombres, ésta, con el correr de los años se convierte en "sabiduría" que trae aparejada la conciencia cada vez más clara de la finitud de la vida y que lo único real es el «aquí y el ahora». Los años en los que se pueden disfrutar a sus criaturas y que éstas realmente lo quieren y necesitan pasan muy rápidamente. Por todas estas razones un 
de los progenitores reduce la jornada —y el sueldo—; o quién de ellos disfruta de excedencia — sin sueldo—, sigue dependiendo de una brecha salarial del $20 \%$ que en todo caso perjudica a las mujeres ${ }^{47}$, y a una segregación vertical y horizontal del mercado de trabajo por sexos ${ }^{48}$.

Es preciso que los planes de igualdad de las empresas evidencien los criterios de mérito y capacidad en el acceso y la permanencia en el empleo, y se realice un seguimiento de tales criterios por los representantes de los trabajadores (art. $47 \mathrm{LOI})^{49}$. Pero, sobre todo, es necesaria una evaluación externa de los resultados de la implementación de tales planes igualdad en materia de acceso y permanencia en el empleo.

La evolución de la realidad social, también precisa que las normas laborales reguladoras de derechos para mujeres por razones biológicas tengan en cuenta otros destinatarios que, de lo contrario, pueden resultar discriminados. Pues si, ciertamente, algunos derechos de conciliación para mujeres como el permiso de lactancia se han convertido en derechos que pueden ejercer los progenitores con independencia del sexo ${ }^{50}$, no ocurre lo mismo con otras medidas de conciliación

número cada vez más creciente de hombres se plantean conciliar las necesidades emocionales con el descanso y con la necesidad de ser efectivos y de tener contacto con hijas e hijos tanto pequeños, como mayores. Es percibido como una fuente de gratificaciones importante, y que va siendo considerado como una parte del patrimonio experiencial y vital, y al cual no desean renunciar», Kaufmann Hahn, A. «Psicología del género. Los orígenes de la desigualdad familiar» (2012), en Carmona Cuenca, E. (2012). Diversidad de Género e igualdad de Derechos, Valencia, Tirant lo Blanch, p. 32.

47 Sobre este dato véase el informe elaborado por UGT: http://www.ugt.es/Publicaciones/ Informe\%20Brecha\%20Salarial-22feb2017-OK. PDF (a. 7/06/2017). En relación con la brecha salarial, véase SÁEz LARA, C. (Coord). VVAA. (2017). Igualdad de género en el trabajo: estrategias y propuestas, Laborum, Murcia, pp. 97-116.

48 Sobre la segregación vertical y horizontal del mercado de trabajo, véase FÁBREGAT MONFORT, G. (2008). La discriminación de género en el acceso al mercado de trabajo. La posibilidad de una nueva tutela a la luz de la LO 3/2007, de 22 de marzo, para la Igualdad Efectiva de Mujeres y Hombres, Valencia, Tirant lo Blanch, pp. 55-62.

49 «Se garantiza el acceso de la representación legal de los trabajadores y trabajadoras o, en su defecto, de los propios trabajadores y trabajadoras, a la información sobre el contenido de los Planes de igualdad y la consecución de sus objetivos. Lo previsto en el párrafo anterior se entenderá sin perjuicio del seguimiento de la evolución de los acuerdos sobre planes de igualdad por parte de las comisiones paritarias de los convenios colectivos a las que éstos atribuyan estas competencias». Sobre requisitos del plan de igualdad y seguimiento de los mismos, véase FÁBREGAT Monfort, G. (2008). La discriminación de género en el acceso al mercado de trabajo. La posibilidad de una nueva tutela a la luz de la LO 3/2007, de 22 de marzo, para la Igualdad Efectiva de Mujeres y Hombres, Valencia, Tirant lo Blanch, pp. 178-197.

50 El artículo 25.5 de la Ley 16/1976, de 8 de abril, de Relaciones laborales, y el artículo 37.4 de la Ley 8/1980, de 10 de marzo, del Estatuto de los Trabajadores mantuvieron la titularidad 
como la suspensión del contrato por maternidad u otros derechos como la solicitud de interrupción del embarazo solo otorgados a las mujeres en detrimento de los hombres transgénero ${ }^{51}$.

La necesidad de armonizar los artículos 14 y $9.2 \mathrm{CE}$ se ha evidenciado con ocasión de los avances científicos que han equiparado a hombres (transgénero) y a mujeres en un rasgo que antes diferenciaba a las mujeres en oportunidades en la vida real (la maternidad). La desaparición de la exclusividad en el rasgo de relevancia jurídica que antes identificaba a las mujeres como destinatarias del derecho (art. 9.2 CE), convierte la medida de acción positiva en una medida discriminatoria por razón de identidad sexual (art. $14 \mathrm{CE}$ ). Así pues, la suspensión del contrato por maternidad para mujeres ya no se justifica en una desigualdad real y efectiva entre hombres y mujeres en ese ámbito vital. La implementación de medidas de acción positiva — exigencia de igualdad real y efectiva entre mujeres y hombres - tiene que cohonestarse con el mandato de igualdad de trato o igualdad formal como prohibición de discriminaciones por razones ad personam; significa que es posible implementar medidas de acción positiva en aquellos ámbitos de la realidad social presente en los que las mujeres son desiguales en oportunidades respecto de los hombres o están siendo perjudicadas en la vida real. Pero significa también que una vez desaparecida la exclusividad en el rasgo que las hacía desiguales en la vida real respecto de los hombres, tal derecho debe ser disfrutado indistintamente por hombres (transgénero) o por mujeres.

También es preciso que la suspensión del contrato por maternidad, de titularidad de la madre, se convierta en un permiso parental por nacimiento de hijo

femenina del permiso de lactancia establecida desde la Ley de 13 de marzo de 1900 sobre protección de la mujeres y el niño en el trabajo. Sin embargo, al no regular propiamente el derecho de amamantamiento sino el de «lactancia» de un hijo menor de 9 meses, se interpretó que en ese concepto se incluía lactancia artificial (STCT de 9 de abril de 1978). La Ley 3/1989, de 3 de marzo, reformó el artículo 37.3 del Estatuto de los Trabajadores añadiendo que «este permiso podrá ser disfrutado indistintamente por la madre o por el padre en caso de que ambos trabajen». Tras la reforma introducida por la Ley 3/2012, de 6 de julio, de medidas urgentes para la reforma del mercado laboral, el permiso de lactancia se configura como un «derecho individual de los trabajadores, hombres o mujeres». Se sustituye, así, la expresión de las «trabajadoras» por la de «los trabajadores».

${ }^{51}$ La LO 2/2010, de 3 de marzo, de salud sexual y reproductiva, y de la interrupción voluntaria del embarazo reconoce el derecho de la mujer solicitar la interrupción de su embarazo (arts. 14 y ss.). Así mismo, el artículo 48.4 RDL 2/2015, de 23 de octubre, por el que se aprueba el texto refundido de la Ley del Estatuto de los Trabajadores, determina que la suspensión del contrato por maternidad es de titularidad de la madre, pudiéndolo compartir con el padre a opción de la interesada. 
que pueda ser disfrutado indistintamente por ambos progenitores, con independencia del sexo, la identidad sexual o la orientación sexual. La finalidad de la norma es el cuidado de los hijos por los progenitores, lo que indirectamente puede incidir en una mayor corresponsabilidad entre mujeres y hombres.

La garantía de la corresponsabilidad parental de los progenitores también debe ser pretexto para convertir esta medida de acción positiva —el descanso por maternidad de titularidad de la madre- en un permiso parental que pueda ser disfrutado de forma simultánea o sucesiva por ambos progenitores, al margen de su sexo, identidad sexual u orientación sexual (permiso parental por cuidado de hijo tras su nacimiento para ambos progenitores sustitutorio del descanso por maternidad).

La finalidad de la norma ya no sería el descanso por parto, con independencia del sexo o identidad sexual, sino el cuidado del hijo en los primeros meses de vida (el permiso parental). La necesidad de corresponsabilizar a los progenitores en las tareas de cuidado determina que la norma tenga en cuenta a todos sus destinatarios. Así pues, vulneraría el artículo 14 CE una norma que en aras de su finalidad — el cuidado parental — no atiende a todos los destinatarios del cuidado: los progenitores, con independencia del sexo u orientación sexual. La STS 84/2017, de 10 de enero (Sala de lo Social, Sección $1 .^{a}$ ) es muy clara al respecto, cuando señala que «la suspensión del contrato de trabajo por la llamada "maternidad" forma parte de un concepto más amplio, aunque innominado en nuestra legislación, cual es el permiso parental, puesto que bajo la genérica — y no siempre apropiada- denominación de "maternidad", se incluyen no solo los supuestos de parto, sino también los de adopción y acogimiento de menores de 6 años, de menores discapacitados o de aquéllos con especiales necesidades de inserción social y familiar. En este segundo caso, el titular del derecho a la suspensión por "maternidad" no necesariamente será de la madre adoptiva o de acogida, pues el mismo se reconoce indistintamente a favor del padre, ambos adoptantes o acogedores se hallan en un mismo nivel de protección. Asimismo, en el caso de parto, se incluye la posibilidad de que el trabajador que suspende su contrato de trabajo no sea la madre, sino el otro progenitor, bien por fallecimiento de ésta, bien por cesión de la madre de todo o parte del periodo - a excepción, en este último caso, de las 6 semanas inmediatamente posteriores al parto-».

En relación con las diferentes manifestaciones de la violencia contra las mujeres por su minusvaloración social, la LO 1/2004 adicionó medidas de acción positiva para mujeres víctimas de la violencia intrafamiliar y de relaciones de pareja con o sin convivencia: el derecho de acceso a la información y a la asistencia social integrada, o el derecho a la asistencia jurídica gratuita. También inclu- 
yó medidas de protección en el ámbito social tales como la posibilitad de su movilidad geográfica, o la suspensión con reserva del puesto de trabajo (Título II). Sin embargo, no estableció medidas de acción positiva para las víctimas de todas las manifestaciones de la violencia de género.

Se podría pensar que tales medidas de acción positiva no son conformes al artículo $14 \mathrm{CE}$ en la medida en que estos derechos solo pueden ser disfrutados por las mujeres maltratadas y no por los hombres maltratados. Es deseable que, a futuro, la norma proteja a todos los destinatarios del maltrato con independencia del sexo de la víctima, y al margen del sexo o identidad sexual del agresor. Sin embargo, dada la incidencia de la violencia contra las mujeres por su diferente valoración como seres humanos, y que la ejecución real de estas políticas depende de los recursos económicos — muchas veces escasos, incluso, para las propias mujeres - la norma debe seguir dando prioridad al grupo de población femenino.

Las leyes autonómicas no solo han enumerado todas las manifestaciones de la violencia de género; también han implementado medidas de acción positiva para las víctimas de todas las expresiones de la violencia machista ${ }^{52} \mathrm{y}$ han incidido en la necesidad de la administración de establecer medidas educativas para prevenir actuaciones violentas con sesgo de género ${ }^{53}$. Pues, ciertamente, las

52 Conforme al Convenio de Estambul de 2011, el artículo 3.1 de La Ley Foral 14/2015, de 10 de abril, para actuar contra la violencia hacia las mujeres determina que «a los efectos de la presente ley foral, se entiende por violencia contra las mujeres la que se ejerce contra éstas por el hecho de serlo o que les afecta de forma desproporcionada como manifestación de la discriminación por motivo de género y que implique o pueda implicar daños o sufrimientos de naturaleza física, psicológica, sexual o económica, incluidas las amenazas, intimidaciones y coacciones o la privación arbitraria de la libertad, en la vida pública o privada». Así mismo, el artículo 3.2 de la Ley Foral 14/2015 enumera las diferentes manifestaciones de la violencia ejercida mayoritariamente contra las mujeres. Esta ley bien precedida de la Ley catalana 5/2008, de 24 de abril, del derecho de las mujeres a erradicar la violencia machista que regula medidas de acción positiva para la víctimas de todas las manifestaciones de la violencia mayormente ejercida contra las mujeres.

${ }^{53}$ El artículo 26.4 de la Ley de 28 de julio, de igualdad de mujeres y hombres de las Islas Baleares determina que «La administración educativa de las Illes Balears garantizará que en todos los centros educativos haya una persona responsable de la coeducación, con formación específica, que impulse la igualdad de género y facilite un mejor conocimiento de los obstáculos y las discriminaciones que dificultan la plena igualdad de mujeres y hombres»; así mismo artículo 26.5 expresa la necesidad de formar a educadores en igualdad de género: «La administración educativa de las Illes Balears garantizará la educación permanente del profesorado en materia de coeducación». De forma novedosa, el artículo 23 de la Ley catalana 17/2015, de 21 de julio, de igualdad efectiva de mujeres y hombres establece la importancia de educar en igualdad en relación con los juegos y los juguetes: artículo 23 de la Ley 17/2015: «Las administraciones públicas de Cataluña con competencias en materia de juegos y juguetes deben emprender cuantas acciones sean necesarias para: a) Sensibilizar e informar sobre la importancia del juego y los juguetes en la transmi- 
normas penales represivas, o las medidas de acción positiva protectoras de las mujeres que sufren este tipo de violencia no conseguirán erradicar definitivamente este problema si no existe una educación en igualdad ${ }^{54}$.

La educación tiene que instruir en la igualdad real y efectiva de hombres y mujeres; pero, sobre todo, tiene que garantizar una educación en igualdad entre hombres y mujeres, pues así lo exige el ideario democrático-constitucional (art. 27.2 CE).

A diferencia de la regulación estatal, y con carácter precedente, las Disposiciones Finales 4 . $^{\mathrm{a}}$ y 5 . $^{\mathrm{a}}$ de la Ley vasca 4/2005, de 18 de febrero, para la Igualdad Efectiva de Mujeres y Hombres (Ley 4/2005) incluyeron una medida de acción positiva que permitió, y sigue permitiendo, a día de hoy, que las listas que presenten los partidos políticos, federaciones y coaliciones tanto a las elecciones al Parlamento vasco como a las elecciones a las Juntas Generales de los territorios históricos de Álava, Guipúzcoa y Vizcaya, estén conformadas al menos por el $51 \%$ de mujeres en cada tramo de 6 puestos, y en el conjunto de la lista de candidatos y candidatas, pudiendo estar conformadas de modo exclusivo por mujeres. La puesta en marcha de la Ley 4/2005 supuso que, por primera vez en la historia, el Parlamento Vasco estuviera conformado por más mujeres que hombres (un $46,7 \%$ de hombres frente a un $53 \%$ de mujeres) tras las elecciones autonómicas de 2005. La gran mayoría mantuvo una representación equilibrada de grupos de población (entre un $45 \%$ y un $55 \%)^{55}$. Estas disposiciones fueron recurridas en inconstitucionalidad, entre otras razones, por vulneración del principio de igualdad como prohibición de discriminaciones por razón de sexo (art. 14 CE).

sión de los estereotipos sexistas. b) Prohibir la comercialización de juegos y juguetes que sean vejatorios para las mujeres, que atenten contra su dignidad, que hagan un uso sexista del lenguaje o que fomenten la agresividad y la violencia entre los niños y adolescentes. c) Promover la edición de libros, juegos y juguetes no sexistas».

${ }^{54}$ El artículo 1.1 de la Ley catalana 5/2008, de 24 de abril, del derecho de las mujeres a erradicar la violencia machista, establece como objeto de la ley no solo la erradicación de la violencia machista; también la remoción de las estructuras sociales y los estereotipos culturales que la perpetúan.

55 Todo ello a pesar de que la composición y la distribución interna de los dos sexos en las listas electorales fue desigual. Únicamente las listas presentadas por Aralar determinaron la alternancia de hombres y mujeres siguiendo el sistema conocido tradicionalmente de listas cremallera; así mismo, las cabezas de lista de los partidos políticos tampoco estuvieron representadas por mujeres. El Partido Comunista de las Tierras Vascas presentó listas exclusivas de mujeres. Sobre los datos de las candidaturas presentadas para las elecciones al Parlamento Vasco de 17 de abril de 2005, véase el BOPV de 22 de marzo de 2005. 
El Tribunal Constitucional (STC 13/2009) justificó esta medida en aras de la igualdad real y efectiva de mujeres y hombres en el ámbito de la participación política (9.2 CE). Determinó que el artículo 44 bis. 1 in fine LOREG permite que en las elecciones de miembros de las Asambleas Legislativas de las Comunidades Autónomas, las leyes reguladoras de sus respectivos regímenes electorales puedan establecer medidas que favorezcan una mayor presencia de mujeres en las candidaturas que se presenten a las Elecciones de las citadas Asambleas Legislativas. Argumenta que el legislador autonómico ha configurado un sistema que pretende corregir una situación de discriminación de la mujer en la vida pública, de tal manera que la interdicción de discriminación en conexión con el artículo 9.2 CE permite la posibilidad de medidas que traten de asegurar la igualdad efectiva de oportunidades y de trato entre hombres y mujeres. Sin embargo, especifica que, por ser una medida de acción positiva, y no una medida antidiscriminatoria, los resultados se tienen que someter a evaluación temporal, de tal forma que si, finalmente, los parlamentos están compuestos solo o mayoritariamente por mujeres en detrimento de la participación política de los hombres, esta medida deberá ser objeto de derogación ${ }^{56}$.

La doctrina se ha alejado del debate en torno a si es la igualdad formal o la igualdad material la que debe imperar en el ámbito de la participación política, para avalar tales medidas, desde la legitimidad del sistema democrático del Estado entendiendo que «la democracia rectamente entendida no puede ser sino democracia paritaria» porque «la democracia paritaria se muestra como una cuestión de legitimidad democrática que surge como tal con la evolución del Estado liberal hacia el Estado democrático ${ }^{57}$.

La norma que establece listas fundamentalmente constituidas por mujeres es también constitucional desde los artículos 14 y 9.2 CE. Es conforme con el artículo 9.2 CE pues en el momento en el que se aprueba la norma había una menor participación política de las mujeres en el parlamento vasco y en las juntas provinciales. También es conforme con el artículo $14 \mathrm{CE}$ porque no existen procesos de selección que objetiven las aptitudes intelectuales y emocionales de los candidatos —el mérito y la capacidad—, lo que haría prevalecer este dato

56 Sobre esta cuestión véase también el comentario a la STC 13/2009 de Torres Muro, I. (2009). «Comentarios a las SSTC 12/2008, de 29 de enero y 13/2009, de 19 de enero, sobre las cuotas electorales. Contenido, recepción y consecuencias». Aequalitas: Revista jurídica de igualdad de oportunidades entre mujeres y hombres, n. ${ }^{\circ} 24,2009$. p. 33.

57 Rodríguez Ruiz, B. (2007). «De la paridad, la igualdad y la representación en el Estado democrático». Revista Española de Derecho Constitucional, n. ${ }^{\circ} 81$, p. 143. Sobre el tránsito del Estado liberal hacia un Estado democrático que incorpora el derecho de sufragio universal masculino y femenino, véase Rodríguez Ruiz., De la paridad..., ob. cit., pp. 143-151. 
objetivo frente al sexo de los candidatos. La valía de los candidatos se presupone pero no se objetiva. Tales medidas de acción positiva tienen que ser sometidas a una evaluación temporal. Significa que la consolidación de parlamentos mayoritariamente femeninos debería redundar en una transformación de esta medida de acción positiva por una medida antidiscriminatoria que incluya porcentajes iguales o equilibrados de hombres y mujeres en las listas que presenten los partidos políticos en el País Vasco conforme a lo exigido por la Ley Estatal.

En la actualidad, las reflexiones doctrinales en torno a la posible reforma de la Constitución aluden a la necesidad de garantizar una democracia paritaria no solo reducida a la representación equilibrada de mujeres y hombres en las instituciones democráticas: también proyectada en la presencia equilibrada de las mujeres en el proceso de reforma constitucional. En este sentido, se sugiere que en los títulos dedicados a los distintos poderes del Estado se incluya el principio de presencia equilibrada de hombres y mujeres en los distintos órganos estatales, así como la obligatoriedad de tener presente la perspectiva de género en todos los procedimientos para la aprobación de normas ${ }^{58}$. También se persigue que los informes de impacto por razón de sexo no solo sean preceptivos para las disposiciones reglamentarias, o para los proyectos de ley: también para las normas que se aprueban por el parlamento estatal y los parlamentos autonómicos ${ }^{59}$.

Finalmente, se recomienda la inclusión de la paridad como mandato de optimización, así como la regulación en el artículo 14 CE de la posibilidad de implementar medidas de acción positiva para corregir las discriminaciones de las mujeres en ámbitos concretos de la realidad social; también se sugiere la

58 El artículo 8 TFUE alude al mainstreaming de género al señalar que en todas las acciones de la Unión Europea se fijará el objetivo de eliminar las desigualdades entre mujeres y hombres, así como promover su igualdad real y efectiva. El artículo 23 de la Carta europea de Derechos Fundamentales también señala que la igualdad entre mujeres y hombres deberá garantizarse en todos los ámbitos. Incorporar la perspectiva de género «significa tener en cuenta en todo momento que existen relaciones de género, y por lo tanto de desigualdad entre mujeres y hombres, así como estereotipos que adscriben comportamientos, características o expectativas diferenciadas a cada uno de los sexos», Alonso Álvarez, A. (2015). El mainstreaming de género en España. Hacia un compromiso transversal con la igualdad, Valencia, Tirant lo Blanch, p. 32

59 Ley 30/2003, de 13 de octubre, sobre medidas para incorporar la valoración del impacto de género en las disposiciones normativas que elabore el Gobierno, modificó los artículos 22.2 y 24.1.b de la Ley 50/1997, de 27 de noviembre, del Gobierno. Esta reforma exige que los proyectos de ley y las disposiciones reglamentarias irán acompañadas de un informe, sobre el impacto por razón de género, de las medidas que contienen. Sin embargo, no incorpora modificaciones para que las proposiciones de ley presentadas por las Cortes Generales, o el pueblo, incorporen un informe de las mismas características, por lo que no se cumple la exigencia de transversalidad de género en todas las normas del ordenamiento. 
alusión constitucional expresa a la necesidad de proteger a las mujeres víctimas de la violencia de género ${ }^{60}$.

\subsection{Medidas represivas con perspectiva de género}

La identificación de la violencia contra las mujeres como violencia de género por ser manifestación de las relaciones de poder históricamente desiguales entre mujeres y hombres derivó en la regulación de medidas represivas con perspectiva de género en la LO 1/2004, de 29 de diciembre, de medidas de protección integral contra la violencia de género (LO 1/2004) ${ }^{61}$. Tales medidas no solo han perseguido - y persiguen - castigar, en mayor medida, al autor masculino de la violencia de género: también pretenden prevenir futuras actuaciones violentas basadas en la diferente valoración social de las mujeres.

La LO 1/2004 incorporó medidas represivas con perspectiva de género consistentes en adicionar, entre los tipos agravados de lesiones, uno que permitiera incrementar la pena cuando las lesiones se produjeran contra quien fuera o hubiera sido la esposa del autor, o mujer que estuviera o hubiera estado ligada a él por una análoga relación de afectividad, aun sin convivencia (art. 148.4 CP); también se decidió incrementar la pena por violencia no habitual (art. 153.1 CP), coacciones (art. 172.2 CP) o amenazas leves (art. 171.4 CP) ${ }^{62}$. Sin embargo, no reguló tal incremento para la violencia habitual, o para todas las manifestaciones de la violencia ejercida mayormente contra las mujeres ${ }^{63}$.

La inclusión del binomio hombre-mujer como sujetos activo y pasivo de este tipo de violencia generó una viva polémica doctrinal y jurisprudencial; entendiendo, así, que las relaciones de dominación que se producen entre el sujeto dominante y el sujeto objeto de dominación, implican, in abstracto, un mayor

60 Salazar Benítez, O. (2017). «Género, poder y ciudadanía». Cuadernos Manuel Giménez Abad, febrero, pp. 67 y 68.

${ }^{61}$ El artículo 1 de la LO 1/2004 señala que el objeto de la ley es «actuar contra la violencia que como manifestación de la discriminación, la situación de desigualdad y las relaciones de poder de los hombres sobre las mujeres, se ejerce sobre éstas por parte de quienes sean o hayan sido sus cónyuges o de quienes estén o hayan estado ligados a ellas por relaciones similares de afectividad, aun sin convivencia» (art. 1).

${ }^{62}$ En este sentido, la LO 1/2004 no garantiza el principio de transversalidad en la medida en que protege solo un tipo de violencia de género, la que se produce en el ámbito familiar o de relaciones de pareja con o sin convivencia, pero no permite incrementar la pena cuando la violencia intrafamiliar es habitual.

${ }_{63}$ Zoco Zabala, C. (2008). Probibición de distinciones por razón de sexo. Derecho comunitario, nacional y autonómico, Cizur Menor, Thomson-Aranzadi, pp. 102 y 103. 
reproche de la conducta desde el punto de vista penal, pero no llevan consigo, inexorablemente, una subsunción en el binomio hombre-mujer ${ }^{64}$.

El Tribunal Constitucional legitimó constitucionalmente tal diferencia penológica entre mujeres (sujeto pasivo) y hombres (sujeto activo). En tal sentido, afirmó que el objetivo de la diferencia penal según quién sea el sujeto activo supone también combatir el origen de un abominable tipo de violencia que se genera en un contexto de patriarcado y desigualdad ${ }^{65}$. En el mismo sentido, la doctrina recuerda que cuando «la violencia de género es ejercida por un hombre contra una mujer, el sujeto activo necesariamente es un hombre y el sujeto pasivo es una mujer; y ello viene condicionado no tanto por el sexo sino por el género, esto es, por la atribución de funciones sociales establecidas por el sistema patriarcal a las personas de sexo masculino y femenino» ${ }^{66}$.

La LO 1/2004 no incluyó medidas represivas con perspectiva de género para todas las manifestaciones de la violencia, mayormente ejercida contra mujeres, ni siquiera para la violencia intrafamiliar habitual ${ }^{67}$. Sin embargo, la LO 1/2015, de 30 de marzo, por la que se modifica la LO 10/1995, de 23 de noviembre, del Código Penal (LO 1/2015) ha incorporado la «razón de género» como causa agravante de discriminación en el artículo 22.4. ${ }^{\mathrm{a}} \mathrm{CP}$. Entendiendo, así, que las actuaciones discriminatorias por razón de género obedecen a «los papeles, comportamientos o actividades y atribuciones socialmente construidos que una sociedad concreta considera propios de mujeres o de hombres» ${ }^{68}$. De tal forma, que cualquier manifestación de la violencia ejercida por hombres puede castigarse con un incremento de pena, si se demuestra que tal violencia obedece a

64 Este fue el fundamento del informe negativo al anteproyecto de LO 1/2004 emitido por el Consejo General del Poder Judicial. Aunque reconoce que el $91 \%$ de la violencia intrafamiliar y de relaciones de pareja con o sin convivencia es ejercida por hombres.

65 SSTC 59/2008; 45/2009; 127/2009; y 41/2010.

66 Ventura Franch, A. (2016). «El Convenio de Estambul y los sujetos de la violencia de género. El cuestionamiento de la violencia doméstica como categoría jurídica». Revista de Derecho Político, n. ${ }^{\circ}$ 97, septiembre-diciembre, p. 196.

${ }^{67}$ La doctrina entendió que, por primera vez, el legislador ha regulado una realidad histórica que sigue estando presente en la actualidad: la violencia intrafamiliar, pues la violencia hacia la mujer se produce principalmente en el seno de la familia, y especialmente en las relaciones de pareja (cfr. VV. AA., Ley de Medidas de Protección Integral contra la Violencia de Género (LO 1/2004, de 28 de diciembre), Iustel, Madrid, 2005, pp. 40 y 41.

68 Convenio del Consejo de Europa sobre prevención y lucha contra la violencia contra las mujeres y la violencia doméstica, Convenio de Estambul, de 11 de mayo de 2011, apartado XXII del preámbulo. 
razones de género. También ha incluido nuevos delitos que son expresión de la violencia mayormente ejercida contra las mujeres ${ }^{69}$.

La inclusión de la causa agravante de género podría llevar aparejada la derogación de las normas penales que obligan al juez a incrementar la pena en los casos de violencia intrafamiliar no habitual, o de relaciones de pareja con o sin convivencia (lesiones, amenazas y coacciones). Pero dado que la violencia contra las mujeres es mayormente ejercida en el ámbito doméstico y de las relaciones de pareja, es posible el mantenimiento de este preceptivo incremento penal que el juez está obligado a aplicar en tales supuestos de violencia machista. También debería ser preceptivo el incremento de la pena para la violencia intrafamiliar habitual, por la mayor repercusión que este tipo de violencia tiene sobre las mujeres.

Las leyes autonómicas también han incidido en la necesidad de la administración de establecer medidas educativas para prevenir actuaciones violentas con sesgo de género ${ }^{70}$. Pues, ciertamente, las normas penales represivas, o las medi-

69 El nuevo Código Penal de 2015 introduce el matrimonio forzado entre las conductas que pueden dar lugar a una explotación de personas, en cumplimiento de la Directiva 2011/36/UE del Parlamento Europeo y del Consejo de 5 abril de 2011, relativa a la prevención y lucha contra la trata de seres humanos y a la protección de las víctimas (art. 172 bis); también se introduce un nuevo tipo penal de acoso dentro de los delitos contra la libertad (acecho u hostigamiento, art. 172 ter CP). Este delito ofrece respuesta a conductas graves que no podían ser consideradas como amenazas o coacciones, dada su gravedad. Se trata de conductas reiteradas por medio de las cuales se menoscaba gravemente la libertad y sentimiento de seguridad de la víctima, a la que se somete a persecuciones o vigilancias constantes, llamadas reiteradas, u otros actos continuos de hostigamiento. La jurisprudencia ha señalado que «(...) este nuevo delito está destinado a ofrecer respuesta a conductas de indudable gravedad que, en muchas ocasiones, no podían ser calificadas como coacciones o amenazas. Se trata de todos aquellos supuestos en los que, sin llegar a producirse necesariamente el anuncio explícito o no de la intención de coartar la libertad de la víctima (coacciones), se producen conductas reiteradas por medio de las cuales se menoscaba gravemente la libertad y sentimiento de seguridad de la víctima, a la que se somete a persecuciones o vigilancias constantes, llamadas reiteradas, u otros actos continuos de hostigamiento», Sentencia del Juzgado de Instrucción n. 3 de Tudela, de 23 de marzo de 2016. Así mismo, se impone pena de prisión permanente revisable para asesinatos precedidos de agresión sexual (140.1.2. $\left.{ }^{\circ} \mathrm{CP}\right)$, y se amplía el ámbito de la medida de libertad vigilada (se añade el art. 140 bis CP) que se podrá imponer en todos los delitos contra la vida y en los delitos de malos tratos y lesiones cuando se trate de víctimas de «violencia de género y doméstica».

${ }^{70}$ El artículo 26.4 de la Ley de 28 de julio, de igualdad de mujeres y hombres de las Islas Baleares determina que «La administración educativa de las Illes Balears garantizará que en todos los centros educativos haya una persona responsable de la coeducación, con formación específica, que impulse la igualdad de género y facilite un mejor conocimiento de los obstáculos y las discriminaciones que dificultan la plena igualdad de mujeres y hombres»; así mismo, el artículo 26.5 expresa la necesidad de formar a educadores en igualdad de género: «La administración educativa 
das de acción positiva protectoras de las mujeres que sufren este tipo de violencia no conseguirán erradicar definitivamente este problema si no se garantiza una educación en igualdad ${ }^{71}$.

La educación tiene que instruir en la igualdad real y efectiva de hombres y mujeres; pero, sobre todo, tiene que garantizar una educación en igualdad entre hombres y mujeres, pues así lo exige el ideario democrático-constitucional (art. 27.2 CE).

\subsection{Medidas antidiscriminatorias}

La prohibición de discriminaciones indirectas por razón de género ha derivado en la implementación de medidas antidiscriminatorias. A diferencia de las acciones positivas que otorgan derechos a las mujeres por ser desiguales en un ámbito concreto de la realidad social presente, las medidas antidiscriminatorias se traducen en normas que persiguen remover las discriminaciones indirectas que producen un perjuicio a las mujeres otorgando iguales o equilibrados porcentajes de derechos a ambos grupos de población.

Las medidas antidiscriminatorias suponen la activación de medidas de igualdad formal para perseguir una igualdad real; no suponen una excepción al principio de igualdad del artículo 14.1 CE, en cuanto a la naturaleza de la ley, pues no otorgan más derechos a las mujeres que a los hombres, o viceversa. Sin embargo, su eficacia normativa es real pues persiguen remover discriminaciones indirectas que sufren las mujeres en ámbitos concretos de la realidad social.

Con el fin de garantizar una participación política de las mujeres (democracia paritaria) en el año 2007 el legislador estatal (Disposiciones adicionales 1.

de las Illes Balears garantizará la educación permanente del profesorado en materia de coeducación». De forma novedosa, el artículo 23 de la Ley catalana 17/2015, de 21 de julio, de igualdad efectiva de mujeres y hombres establece la importancia de educar en igualdad en relación con los juegos y los juguetes: artículo 23 de la Ley 17/2015: «Las administraciones públicas de Cataluña con competencias en materia de juegos y juguetes deben emprender cuantas acciones sean necesarias para: a) Sensibilizar e informar sobre la importancia del juego y los juguetes en la transmisión de los estereotipos sexistas. b) Prohibir la comercialización de juegos y juguetes que sean vejatorios para las mujeres, que atenten contra su dignidad, que hagan un uso sexista del lenguaje o que fomenten la agresividad y la violencia entre los niños y adolescentes. c) Promover la edición de libros, juegos y juguetes no sexistas».

${ }^{71}$ El artículo 1.1 de la Ley catalana 5/2008, de 24 de abril, del derecho de las mujeres a erradicar la violencia machista, establece como objeto de la ley no solo la erradicación de la violencia machista; también la remoción de las estructuras sociales y los estereotipos culturales que la perpetúan. 
y 2. ${ }^{a}$ de la Ley Orgánica 3/2007, de 22 de marzo, para la Igualdad Efectiva) incorporó una medida antidiscriminatoria obligando a los partidos políticos a incorporar porcentajes equilibrados de participación de hombres y mujeres en las listas que se presentan los partidos en las elecciones europeas, generales (Congreso de los Diputados) y autonómicas (art. 44 bis LOREG) ${ }^{72}$.

Se estableció, así, la obligación de incorporar una representación equilibrada de al menos un $40 \%$ y, como máximo un $60 \%$, de cualquiera de los dos grupos de población en cada tramo de cinco puestos. Por su parte, la Disposición Adicional 2. ${ }^{a}$ que adiciona un nuevo artículo 44 bis a la Ley Orgánica 5/1985, de 19 de junio, del Régimen Electoral General (en adelante LOREG) exigió que dicha proporción equilibrada para las listas que concurran a las elecciones europeas, nacionales (Congreso de los Diputados), autonómicas y municipales, respetase dicho porcentaje en cada tramo de cinco puestos. De tal manera, que cuando el número de puestos a cubrir fuera inferior a cinco, la proporción de mujeres y hombres se acercara a dicho porcentaje en la medida de lo posible.

Esta excepción determinó cierta carencia de transversalidad, pues idéntico criterio de paridad deberían reunir las listas de partidos con poca representación, a salvo las conformadas por uno o dos candidatos, en la medida en que en estos casos es imposible garantizar el criterio de composición equilibrada (sino idéntica) de mujeres y hombres. La ausencia de tales porcentajes para el Senado puede justificarse en que en las islas menores se elige un solo senador, o en Ceuta y Melilla 2 senadores. También puede fundarse en que las listas son abiertas, de tal forma que los criterios de composición equilibrada se deberían trasladan al elector de circunscripciones que eligen 3 senadores al que la LOREG no le obliga a elegirlos conforme a criterios de paridad. Sin embargo, la necesidad de una consagración legal de porcentajes equilibrados al elector, no es obstáculo para que la norma también imponga a los partidos políticos porcentajes equilibrados de mujeres y de hombres en las listas que presenten para elegir senadores.

La exigencia de una composición equilibrada de las listas que concurren a las elecciones fue objeto de recursos de amparo ante el Tribunal Constitucional con ocasión de las elecciones municipales de 2007; unas veces porque las listas

72 Hasta la aprobación de la LOREG la presencia de las mujeres es testimonial. Así, por ejemplo, en 1977, el número de mujeres en el Congreso de los Diputados es del 5.71\%; o del $6.30 \%$ en 198. Sobre la inclusión del artículo 44 bis LOREG, véase SEvilla Merino, J. (2007). «Paridad y leyes electorales», en Figueruelo Burrieza, A. Ibáñez Martínez, M. L. Merino Hernández, R. M. (Editoras). Igualdad ¿Para qué? A propósito de la LO para la igualdad de mujeres y hombres, Granada, Comares, pp. 501-508. 
incluían más mujeres que el porcentaje equilibrado establecido en la ley; y otras, porque las listas sobrepasaban el número de hombres 73.

En lo que aquí interesa, dicha norma fue recurrida y cuestionada en inconstitucionalidad por vulneración de la exigencia de igualdad formal del artículo $14 \mathrm{CE}^{74}$. Entendiendo que esta política que los recurrentes califican de forma incorrecta como «discriminación inversa» es discriminatoria porque impide integrarse en las listas al que, pese a desearlo, pertenezca a un grupo de población cuyo número de candidatos haya sobrepasado el porcentaje legalmente exigido.

El Tribunal Constitucional estableció que tal medida no comporta una discriminación por razón de sexo ex artículo 14 CE. Aduce que el artículo 44 bis LOREG no incluye un tratamiento diferenciador por razón del sexo de los candidatos, pues las proporciones de participación se establecen por igual para los hombres que para las mujeres.

El análisis de la doctrina sobre esta sentencia corrige, por primera vez, la calificación de medida de acción positiva —o de discriminación inversa- que los recurrentes asignaron al mandato contenido en el artículo 44 bis LOREG. Se afirma, así, que la obligatoriedad de un porcentaje equilibrado de hombres y mujeres no es una medida de acción positiva consistente en derechos para las mujeres pues impide la elaboración de listas que estén conformadas solo o mayoritariamente por hombres, pero también proscribe listas exclusivas o mayoritariamente conformadas por mujeres, como se evidencia en la resolución favorable de recursos de amparo que fueron presentados por sobrepasar, indistintamente, porcentajes de mujeres o de hombres en la conformación de las listas municipales conforme al criterio establecido en el artículo 44 bis LOREG. Se trata, por tanto, de una medida antidiscriminatoria, destinada a remover una discriminación indirecta, en virtud de la cual la presencia de las mujeres en órganos representativos sigue siendo escasa.

La doctrina también ha señalado que, desde la perspectiva de la naturaleza de la norma, la medida antidiscriminatoria no supone una excepción al principio de igualdad formal (14 CE) en aras del artículo 9.2 CE, porque la norma no otorga derechos de participación política solo para mujeres. En este sentido, se afirma que el artículo 9.2 CE juega, un papel más limitado ${ }^{75}$. Aunque algunos

73 SSTC 96/2007, 97/2007, 98/2007, 99/2007, 100/2007, 101/2007, 102/2007, 103/2007, 104/2007, 105/2007, 106/2007, 107/2007, 108/2007.

74 La cuestión y el recurso de inconstitucionalidad presentado por 50 diputados fueron resueltos en una misma sentencia del Tribunal Constitucional (STC 12/2008).

75 Biglino Campos, P. (2008). «Variaciones sobre las listas electorales de composición equilibrada. Comentario a la STC 12/2008». Revista Española de Derecho Constitucional. n. ${ }^{\circ}$ 83, mayo-agosto, pp. 286 y 287: «(...) las listas equilibradas no son medidas de acción positiva, si por 
autores inciden en la eficacia real y efectiva que la medida pretende. De este modo, se subraya que la obligación de los partidos políticos de establecer porcentajes equilibrados en las listas, persigue la igualdad real y efectiva en un ámbito — el de la participación política — en el que las mujeres han sido ignoradas con base en la costumbre de asignación de funciones representativas a los hombres ${ }^{76}$.

Con el fin de dotar a esta norma de mayores garantías de eficacia, se propuso la modificación para que el porcentaje equilibrado de mujeres y hombres se convirtiera en un 50\%. También para establecer listas «cremallera» de alternancia de sexo en las listas. En la actualidad, las listas cremallera vuelve a ser objeto de discusión en la subcomisión del Congreso de los Diputados ${ }^{77}$. En algunas Comunidades Autónomas como Andalucía, el porcentaje equilibrado de hombres y mujeres en las listas conforme a los establecido en el artículo 44 bis LOREG incluye la necesidad de que las listas alternen los sexos; es lo que se conoce como «listas cremallera» ${ }^{78}$.

La garantía constitucional de esta medida antidiscriminatoria — ha señalado la doctrina - se fundamenta en la legitimidad democrática que se origina con

tal se entienden aquellas destinadas a "prevenir o compensar una situación de "desventaja" que tradicionalmente afectan a las mujeres, estableciendo una disciplina jurídica diferenciada a favor de las mismas que es, a veces, una excepción al principio de igualdad formal»; sobre esta cuestión véase también Biglino Campos, P. (2004). «Acerca de la constitucionalidad de las cuotas paritarias», en Balaguer Callejón, M. L. (Coord.). XXV Aniversario de la Constitución Española, Propuestas de Reforma, Málaga, pp. 363-364.

76 Martínez Alarcón señala que « la formulación aparentemente neutra (abstracta) de la medida no puede esconder su verdadera finalidad que no es otra que la de compensar (como pretenden las acciones positivas — affirmative actions — y, más allá, las denominadas medidas de discriminación inversa — reverse discrimination—) la situación de desigualdad existente entre hombres y mujeres en el acceso a los cargos representativos, una finalidad ésta que, por otra parte, se desprende del propio texto de la sentencia del Tribunal Constitucional (...)», Martínez Alarcón, M. L. (2008). «Comentario a la Sentencia del Tribunal Constitucional 12/2008, de 29 de enero, sobre la Ley Orgánica para la Igualdad efectiva de mujeres y Hombres». Teoría y Realidad Constitucional, n. ${ }^{\circ} 22$, p. 609.

77 http://www.expansion.com/agencia/europa_press/2017/05/09/20170509125355.html (a. 8/06/2017).

78 Así, por ejemplo, el artículo 23 de la Ley Electoral andaluza tras la reforma llevada a cabo por la Ley 5/2005, de 8 de abril obliga a que las candidaturas electorales se compongan siguiendo el criterio conocido como «lista cremallera»; ello consiguió resultados positivos en las elecciones autonómicas celebradas el 22 de marzo de 2015, al elevarse el porcentaje de mujeres representadas (un $51,37 \%$, es decir, 59 diputadas y 50 diputados). Sobre esta cuestión véase SALAZAR BENíTEZ, O. (2015), «Ciudadanía, género y poder: la paridad como principio constitucional», Cuestiones de género: de la igualdad y la diferencia, n. ${ }^{\circ} 10$, pp. 18 y 19. 
el paso del Estado liberal hacia el Estado democrático ${ }^{79}$. También resulta conforme a los artículos 9.2 y $14 \mathrm{CE}$ en la medida en que no existen pruebas objetivas de méritos que valoren las aptitudes racionales y emocionales para ser un buen político, lo que impediría que se pudieran establecer porcentajes de hombres y mujeres; el mérito de los candidatos se presupone, en aras de conseguir escaños, pero no se objetiva. En este sentido, no se puede presumir que las cuotas cercenan el derecho fundamental de sufragio pasivo del varón preterido (vulneración de la igualdad formal); como tampoco se puede argumentar que las cuotas obligan a buscar mujeres sospechosamente «menos meritorias» que los hombres, pues la misma suposición de ausencia de mérito se podría predicar de los hombres.

\section{CONSIDERACIONES FINALES}

Durante todos estos años se ha evolucionado en la derogación de normas que ignoran a las mujeres en derechos o las perjudican en la vida real. También se ha avanzado en normas que aprueban medidas de acción positiva, medidas antidiscriminatorias y medidas represivas con perspectiva de género en aras de una igualdad real y efectiva entre mujeres y hombres.

Los avances normativos, sin embargo, no han perseguido eliminar la discriminación interseccional que resulta de la confluencia de la discriminación por ser mujer con otras discriminaciones por razones subjetivas. Las leyes autonómicas han desarrollado el concepto de «discriminación múltiple» en leyes que, sin embargo, tienen por objeto erradicar un solo tipo de discriminación (por razón de identidad de género, de identidad sexual, o de orientación sexual). Es preciso que la discriminación interseccional se regule en una norma transversal que incluya un protocolo único para el reconocimiento y tratamiento conjunto de todas las discriminaciones padecidas por la víctima. También para determinar cuáles son las medidas de acción positiva que resultan de la interacción de todas las discriminaciones.

La evolución social también debe ser fundamento para la conversión de medidas de acción positiva para mujeres en medidas que puedan disfrutar hombres (transgénero) y mujeres cuando desaparece la exclusividad en el rasgo que antes las hacía desiguales en oportunidades en la vida real (la maternidad). De lo contrario, tal medida de acción positiva puede resultar discriminatoria por razón de identidad sexual (art. $14 \mathrm{CE}$ ) porque la finalidad de la ley (el descanso por parto) ya incluye a todos sus destinatarios (los y las gestantes).

79 Rodríguez Ruiz., De la paridad..., ob. cit., pp. 143. 
Al mismo tiempo, se determina que en una sociedad de ciudadanas y ciudadanos que trabajan la finalidad mutante de los derechos de conciliación - la corresponsabilidad parental — debe convertir el derecho a la suspensión del contrato por maternidad, de titularidad de la madre, en un derecho que pueda ser disfrutado, de forma sucesiva o simultánea por cualquiera de los progenitores con independencia de su orientación o identidad sexual; la letra de la ley debe ser acorde con su mutante finalidad — la corresponsabilidad parental — incluyendo a todos sus destinatarios (los progenitores).

Los avances normativos no siempre han redundado en buenos resultados. En líneas generales, la mayoría de los derechos de conciliación pueden ser disfrutados por hombres y mujeres indistintamente; sin embargo, la demanda mayoritaria de estas medidas sigue siendo femenina porque la decisión sobre quién de los progenitores reduce la jornada — y el sueldo—; o quién de ellos disfruta de excedencia — sin sueldo—, sigue dependiendo de una brecha salarial del $20 \%$ que en todo caso perjudica a las mujeres. Así mismo, se observa que las mujeres siguen siendo víctimas mayoritarias de la violencia que los hombres ejercen contra ellas por su diferente valoración como seres humanos.

Las políticas públicas deben ir dirigidas a garantizar que las mujeres sean iguales en las condiciones de partida del proceso selectivo. Pero, sobre todo, deben estar destinadas a garantizar una educación que se proyecte en la importancia de formar ciudadanos y ciudadanas iguales ante los retos laborales e iguales en su consideración como personas

Los avances normativos también deben perseguir una educación en igualdad conforme a los objetivos previstos en el artículo 27.2 CE. Así pues, es preciso una reforma de la Ley Orgánica 8/2013, de 9 de diciembre, para la mejora de la calidad educativa que incluya materias de igualdad obligatorias en las diferentes fases del currículo escolar, de tal forma que las políticas para la formación e instrucción en igualdad no queden al albur de la voluntad política.

Title:

Equality between women and men after forty years of the Spanish Constitution.

\section{Summary:}

1. Introduction. 2. Formal and material meaning of equality between women and men: the harmonization of arts. 14 and 9.2 EC. 3. Formal equality: prohibition of direct and indirect discrimination on grounds of sex. 4. Material equality. 4.1 Positive action measures. 4.2 Repres- 
sive measures with a gender perspective. 4.3 Anti-discrimination measures. 5. Final considerations.

\title{
Resumen:
}

En este trabajo se analiza la evolución de la pretendida igualdad efectiva entre mujeres y hombres en la legislación y en la jurisprudencia, desde el doble significado formal (art. 14 CE) y material (art. 9.2 CE) de la exigencia de igualdad constitucional. La prohibición de discriminaciones por razón de sexo ha redundado en la derogación de normas que ignoran a las mujeres en la consecución de derechos o que las perjudican en la vida real. Sin embargo, no ha repercutido en la prohibición legal expresa de la discriminación múltiple como discriminación interseccional que resulta de la confluencia de otras discriminaciones con el hecho de ser mujer. La exigencia de igualdad real y efectiva de mujeres y hombres ha redundado en medidas de acción positiva, medidas represivas con perspectiva de género y medida antidiscriminatorias compatibles con las exigencias de los artículos 14 y 9.2 CE. Sin embargo, no ha repercutido en garantías efectivas de instrucción y formación en igualdad de obligado cumplimiento. Tampoco se ha proyectado en una regulación transversal de medidas de acción positiva que permitan erradicar la discriminación interseccional como discriminación cualitativamente diferente. La evolución social determina la necesidad de revisar algunas medidas de acción positiva para las mujeres desde la perspectiva de la prohibición de discriminaciones por otras razones subjetivas (la identidad sexual) y desde el objetivo real de las medidas de conciliación de la vida personal y familiar: la corresponsabilidad parental. Se verifica la necesidad de transformar algunas medidas de acción positiva para mujeres (suspensión del contrato por maternidad) en derechos que puedan ser disfrutados por los gestantes, con independencia del sexo o identidad sexual. También se determina la necesidad de convertir tales derechos para gestantes en medidas de corresponsabilidad parental que puedan ser disfrutadas de modo simultáneo o sucesivo por ambos progenitores.

\begin{abstract}
:
This paper analyzes the evolution of effective equality between women and men in legislation and jurisprudence from the formal and material meaning of the constitutional requirement of equality. The prohibition of discrimination on the grounds of sex has resulted in the repeal of rules that ignore women in the pursuit of rights or that harm them in real life. However, it has not affected the legal prohibition of multiple discrimination as intersectional discrimina-
\end{abstract}


tion resulting from the confluence of other discriminations with the fact of being a woman. The demand for real and effective equality of women and men has resulted in positive action, repressive actions with a gender perspective and antidiscrimination measures compatible with the requirements of arts. 14 and 9.2 EC. However, effective guarantees of education and training in equality have not been regulated, but rather, voluntary policies that do not translate obligations of prescriptive compliance. Neither is there a transversal regulation of positive actions that allow to eradicate multiple discrimination as qualitatively different discrimination. Likewise, social and scientific evolution has determined the revision of some measures of positive action for women from the perspective of prohibition of discrimination for other subjective reasons (the sexual identity) and from the real objective of labor rights of care: parental co-responsibility of the parents. There is a need to transform some measures of positive action for women (suspension of maternity contract) in rights that can be enjoyed by pregnant women, regardless of sex or sexual identity. It is even determined the need to convert such rights for pregnant women into measures of parental co-responsibility that can be enjoyed indistinctly by both parents.

\section{Palabras clave:}

Discriminación directa; discriminación indirecta; discriminación múltiple; medidas de acción positiva; medidas antidiscriminatorias.

\section{Key words:}

Direct discrimination; indirect discrimination; multiple discrimination; positive discrimination; anti-discrimination actions. 